NBER WORKING PAPER SERIES

\title{
SUBJECTIVE EXPECTATIONS AND DEMAND FOR CONTRACEPTION
}

\author{
Grant Miller \\ Áureo de Paula \\ Christine Valente \\ Working Paper 27271 \\ http://www.nber.org/papers/w27271 \\ NATIONAL BUREAU OF ECONOMIC RESEARCH \\ 1050 Massachusetts Avenue \\ Cambridge, MA 02138 \\ May 2020
}

\begin{abstract}
Funding from the Bill and Melinda Gates Foundation is gratefully acknowledged (Grant number OPP1171956). IRB Number 59/CNBS/2017 approved by the Mozambican Health Ministry's National Bioethics Committee (CNBS) on September 22 2017, updated December 14 2017. We thank Sergio Chicumbe and Acácio Sabonete at the Instituto Nacional de Sáude, Páscoa Wate at the Ministry of Health, the district health authorities of Maputo City, Maputo Province, and Gaza Province as well as Marina Bassi, Humberto Cossa, and Peter Holland at the Human Development division of the Maputo World Bank office for their support. Thanks go to Yolanda Chongo, Andreas Kokott, Gisela Lourenço, Duelo Macia, and Alfredo Matusse at Intercampus for excellent fieldwork. Manuel Antonio Sanchez Garcia provided outstanding research assistance. For their useful comments, we thank Adeline Delavande and Matthew Wiswall and audiences at the World Bank Maputo Office, University of Bristol, and ECARES. The views expressed herein are those of the authors and do not necessarily reflect the views of the National Bureau of Economic Research.
\end{abstract}

NBER working papers are circulated for discussion and comment purposes. They have not been peer-reviewed or been subject to the review by the NBER Board of Directors that accompanies official NBER publications.

(C) 2020 by Grant Miller, Áureo de Paula, and Christine Valente. All rights reserved. Short sections of text, not to exceed two paragraphs, may be quoted without explicit permission provided that full credit, including $\odot$ notice, is given to the source. 
Subjective Expectations and Demand for Contraception

Grant Miller, Áureo de Paula, and Christine Valente

NBER Working Paper No. 27271

May 2020

JEL No. D83,J13,J16

\begin{abstract}
$\underline{\text { ABSTRACT }}$
Nearly one-quarter of married, fertile-age women in Sub-Saharan Africa say that they want to avoid pregnancy but are not using contraceptives. To the best of our knowledge, this paper is the first to study this puzzle in a developing country using detailed data on women's subjective probabilistic beliefs about contraception and contraceptive attributes. Policy counterfactuals based on a structural model suggest that costly interventions such as eliminating supply constraints would only have modest effects on contraceptive use. Alternatively, increasing partners' approval of methods, aligning partners' fertility preferences with women's, and correcting women's expectations about pregnancy risk absent contraception have the potential to increase use considerably. We provide additional empirical support for this last result through a before/after experiment in which we find that simply (and effectively) informing women about underlying pregnancy risk increases stated intentions to use contraception substantially, in line with our initial estimates.
\end{abstract}

Grant Miller

CHP/PCOR

Stanford University

117 Encina Commons

Stanford, CA 94305-6019

and NBER

ngmiller@stanford.edu

Áureo de Paula

University College London

Department of Economics

Gower Street

WC1E 6BT

United Kingdom

and Institute for Fiscal Studies

a.paula@ucl.ac.uk

\author{
Christine Valente \\ University of Bristol \\ Department of Economics \\ Priory road complex \\ Priory road \\ Bristol, BS8 1TU \\ United Kingdom \\ christine.valente@bristol.ac.uk
}




\section{Introduction}

Total fertility rates in low-income countries remain high, averaging 4.6 children per woman (as of 2017, World Development Indicators, 2019). Importantly, these appear markedly higher than desired by women: in nationally representative surveys, about one quarter of married, fertile-age women in these countries state that they do not wish to become pregnant, but they are not using contraceptives either - a phenomenon commonly referred to as "unmet need for family planning". This results in over 52 million unwanted pregnancies and about 70,000 maternal deaths due to, e.g., unsafe abortions each year (Singh et al., 2014). In response, intensive policy efforts and growing amounts of international aid focus on family planning programs (from under $\$ 400 \mathrm{M}$ prior to 2008 to $\$ 886 \mathrm{M}$ in 2013 according to Grollman et al., 2018). However, there is surprisingly little systematic evidence about why this so-called "unmet need" persists.

There are a variety of potential explanations. Perhaps the most obvious lies on the supply-side, the primary policy focus: ${ }^{1}$ modern contraceptives may simply not be readily available. Notably, however, fewer than $10 \%$ of married women with "unmet need for family planning" across 52 low-income countries cite high cost or inadequate supply as the primary reason for not using contraceptives (Sedgh et al., 2016). ${ }^{2}$ On the demand side, high fertility is strongly correlated with high desired fertility (Pritchett, 1994), but very little is known in quantitative terms about the causes of the gap between women's fertility intentions and contraceptive use. The four main reasons given by women with an "unmet need" for not using contraceptives are: side effects (26\%), infrequent sex (24\%), "opposition" by themselves, their partner, or others close to them (23\%), and breastfeeding/amenorrhea (20\%) (Sedgh et al., 2016). The question of male involvement in family planning decisions has received attention in the public health literature (e.g. Shattuck et al., 2011; Vouking et al., 2014; Raj et al., 2016; Doyle et al., 2018) and in a small number of carefully designed experimental economic studies. Ashraf et al. (2014) and Ashraf et al. (2018) demonstrate that men's higher fertility preferences and/or disap-

\footnotetext{
${ }^{1}$ See, e.g., Blumenthal et al. (2010); Zakiyah et al. (2016); United Nations (2019).

${ }^{2}$ There are a few exceptions to this rule in Central and Western Africa.
} 
proval of contraceptive injections contribute substantially to low contraceptive use in Zambia, and Cassidy et al. (2020) find that introducing female condoms, which are preferred by men, increases the ability of women with low bargaining power to use condoms in a Mozambican slum. ${ }^{3,4}$ But no study of which we are aware aims to rigorously quantify the role of specific barriers to contraceptive use other than male opposition, providing little guidance on what strategies to prioritize.

Given this, there may be neglected 'low-hanging fruits' in addressing "unmet need" for family planning (FP) through empirically-informed strategies targeting specific obstacles that inhibit contraceptive demand. For example, nearly half $(44 \%)$ of the women not using contraceptives despite desiring to avoid pregnancy either cite breastfeeding/amenorrhea or infrequent sex as the primary reason for not using contraception, and may therefore incorrectly believe that they face a low risk of pregnancy (Sedgh et al., 2016). ${ }^{5}$ If women systematically underestimate pregnancy risk absent contraception, then simply recalibrating their beliefs may increase contraceptive use.

In this paper, we collect detailed data on the subjective expectations and probabilistic beliefs of women in Mozambique to study the role of both supply- and demand-side determinants of contraceptive choice among women not wishing to become pregnant. Our rich data allow us to estimate a structural model quantifying women's preferences over a broad set of contraceptive choices and attributes. These estimates, in turn, allow us to predict how contraceptive use would respond

\footnotetext{
${ }^{3}$ The public health literature tends to support the conclusion that involving men is effective in increasing contraceptive use, but the holistic nature of the interventions studied makes it difficult to pinpoint the reason for the change. In the intervention evaluated by Shattuck et al. (2011), for instance, male peers are trained to target men with messages encompassing the financial and health-related benefits of limiting fertility, information about contraceptive methods, and to carry out activities aimed at changing gender norms and improving spousal communication.

${ }^{4}$ Studying an intensive 2-year radio campaign promoting family planning in Burkina Faso and also giving women radios, Glennerster et al. (2019) find that contraceptive use increases by 5.3 percentage points, and they suggest that this was primarily due to improved knowledge about the side effects of modern contraceptives (and ending the myth that modern contraceptives cause sterility).

${ }^{5}$ Nearly half $(47 \%)$ of women reporting infrequent sex as a reason for not using contraception report having sex in the preceding three months. Most women reporting breastfeeding or postpartum amenorrhea as the main reason for not using contraception do not meet the World Health Organization (WHO) criteria for lactational amenorrhea as protection against pregnancy (Sedgh et al., 2016).
} 
to a wide range of potential technologies and FP program strategies. Finally, as part of our survey we conduct a before/after experiment informing women about the average risk of pregnancy in the population absent contraception, allowing us both to estimate the effect of this information on beliefs about pregnancy risk and intentions to use contraception in the future and to assess the validity of our model predictions.

In doing so, we make three key contributions to existing literature. First, to the best of our knowledge, our study is the first to collect data from women in a developing country on their probabilistic beliefs about contraception and pregnancy (including the efficacy, availability, attributes, and side-effects of specific contraceptive methods as well as beliefs about their partners' preferences). ${ }^{6}$ Importantly, our setting is one in which beliefs, preferences, and both economic and societal constraints are likely to differ substantially from those previously studied (Delavande (2008) studying the United States and Nakamura (2016) studying Japan). ${ }^{7}$ Beliefs data, when available, allow preferences to be disentangled from expectations without assumptions about these expectations - e.g., that the subjective expectation used by the individual when making decisions is equal to the average outcome observed in the population. Despite their potential advantages, economic studies incorporating beliefs data remain scarce. ${ }^{8}$ Our data indicate that women generally hold accurate (or plausible) beliefs along many dimensions, but they systematically underestimate both the probability of pregnancy absent contraception and the efficacy of hormonal contraceptives (in the latter case, by as much as 3-5 times the true efficacy for injections and implants, respectively). This suggests that correcting mistaken beliefs may be an effective strategy for increasing contraceptive use.

\footnotetext{
${ }^{6}$ Beliefs about contraception are discussed extensively in the literature (Williamson et al., 2009; WHO/RHR and CCP, Knowledge for Health Project, 2018; Adelekan et al., 2014), but they are not generally numerically quantified. In high-income countries, Delavande (2008) and Nakamura (2016) study subjective beliefs on contraception for women in the US and Japan, respectively.

${ }^{7}$ Mumah et al. (2018) also estimates the effect of binary beliefs about contraceptive methods - e.g., whether the respondent believes the pill to be "effective" or "not effective" in preventing pregnancy - on intended use of these methods among slum dwellers in Nairobi.

${ }^{8}$ Other studies complementing choice data with beliefs include Álvarez and Vera-Hernández (2013), Bennear et al. (2013) and Delavande and Kohler (2015) on health; Wiswall and Zafar (2015), Boneva and Rauh (2019) and Delavande and Zafar (forthcoming) on education; Van der Klaauw and Wolpin (2008) on savings and retirement; and Van der Klaauw (2012) on teachers career decisions.
} 
Second, using our data on subjective expectations, we develop a tractable structural model of contraceptive decision-making in which we incorporate women's beliefs in a consistent and transparent manner into an expected utility decision model. Specifically, we estimate a random utility model of the choice between no contraception, male condoms, injections, implants, and oral contraceptives. In doing so, we quantify the role of each option's attributes (including among others protection against pregnancy, probability of side effects, probability of approval by partners) on women's choices among these five alternatives. Then, focusing on the main reasons that women explicitly report in international surveys for not using contraception (despite not wanting to become pregnant), we predict the impact of a variety of potential strategies for promoting contraceptive use.

Our results are striking. We find that more-of-the-same supply-side interventions are unlikely to effectively increase use: even the most dramatic (and costly) increase in supply, removing all direct and indirect monetary costs of contraceptives, eliminating waiting times, and removing uncertainty about availability increases contraceptive prevalence by only 1.1 percentage points. Similarly, new technologies with no side effects (and accurate beliefs among women about the absence of side effects) increases contraceptive prevalence by about 0.3 percentage points. Alternatively, changing men's fertility preferences and their 'approval' of contraceptives is more effective. Aligning fertility preferences between women and their partners increases contraceptive prevalence by 2.4 percentage points, and increasing women's expectations that their partners will approve available forms of contraception by 25 percentage points raises contraceptive prevalence by 3.6 percentage points. ${ }^{9}$ Finally, correcting beliefs about pregnancy risk absent contraception by 25 percentage points among women who underestimate this risk raises contraceptive use by about 4.9 percentage points among this group and by 1.9 percentage points overall. Importantly, while these latter increases may seem small, they represent substantial progress compared to the current slow pace of change.

\footnotetext{
${ }^{9}$ Studying Zambian women receiving vouchers for contraceptive injections either alone or in the presence of their husband, Ashraf et al. (2014) find that women are $25 \%$ less likely to use concealable contraceptives and more likely to give birth if their husbands know that they received a voucher, demonstrating that men's higher fertility preferences and/or disapproval of injections contribute to low contraceptive use.
} 
As a point of comparison, the increase in contraceptive prevalence among married women observed in Mozambique between 2003 and 2015 was only 4 percentage points (MISAU, INE and ICF, 2016).

Our third contribution is then to build on and validate the results from our structural model by providing experimental evidence. Because changing men's fertility preferences or approval of contraceptive methods may be difficult in practice, we instead focus on correcting women's mistaken beliefs about the probability of pregnancy absent contraception. In doing so, we experimentally test an implication of our model, and we also provide further evidence on the impact of a novel, readily scalable, low-cost information intervention which simply provides information to women about the WHO reference risk of pregnancy within 12 months when not using contraception ( $85 \%$, communicated as "17 out of 20 women"). We find that in response, women realign their probabilistic beliefs with this population statistic and increase their stated intention to use contraceptives in the future. ${ }^{10}$ Among women not using contraceptives at the time of interview, this effect is large, raising intentions to use contraceptives by 8.2 percentage points. Although stated intentions may not reflect revealed preferences, we conduct a validation exercise comparing our experimental estimates with our model predictions and find remarkably consistent estimates.

As noted by Todd and Wolpin (2006), no single randomized controlled trial is likely to be able to determine which of many alternative policies would be the most effective or cost-effective. This seems especially true when there are many possible alternative policies with no clear a priori ranking, which is the case here given the dearth of quantitative evidence on the causes of low contraceptive prevalence in developing countries. In this context, the key advantage of our structural exercise

\footnotetext{
${ }^{10}$ Wiswall and Zafar (2015) also carry out an informational experiment providing detailed population statistics - to a sample of undergraduate students on labor market outcomes by major — and exploit the before-after treatment change in beliefs. Contrary to beliefs about the returns to major choice studied in Wiswall and Zafar (2015), however, we find that, for pregnancy risk, women have a very large elasticity of beliefs to population-level information. Also departing from Wiswall and Zafar (2015), we do not use the panel variation in beliefs in our structural estimation. This is not problematic here since our model exploiting cross-sectional variation in beliefs does not appear to be affected by a concerning degree of omitted variable bias - to the extent that the effect of the change in beliefs observed experimentally on contraceptive use as predicted by the model is of a similar size to the effect on intended contraceptive use observed in the experiment.
} 
is that it enables us to shed light on the effect of many more potential policies than only the particular one we experiment with, and hence guide ours as well as future research in the area. In the spirit of, e.g., Todd and Wolpin (2006); Attanasio et al. (2011); Duflo et al. (2012); Lise et al. (2015), we appraise the validity of our model assumptions using experimental data, which bolsters our confidence in the policy counterfactuals based on our model.

Our work is also related to the broader literature on the effect of providing information on beliefs and behaviors. A rich body of work has produced mixed experimental evidence of the effect of providing information on health and education beliefs and behaviors in developing countries (as recently reviewed by Dupas and Miguel, 2017; Muralidharan, 2017). While there is no simple answer to the question of why information provision has an effect on behavior in some cases but not others, three key considerations are whether: (i) baseline beliefs depart from the information provided, (ii) this information is trusted and relevant, and (iii) other constraints need to be lifted for individuals to act upon their revised beliefs (e.g., by decreasing monetary costs). ${ }^{11}$ Our beliefs data show that baseline beliefs do depart from population statistics, while our results indicate that women trust the information provided in our experiment and find it relevant. ${ }^{12}$ In addition, we ask respondents the extent to which they would trust a message about pregnancy risk coming from a variety of sources, and answers suggest a high degree of trust in health professionals (and, to a lesser extent, in the media). There is therefore reason to believe that making the pregnancy risk information salient within the context of health counseling and/or TV or radio programs could be effective ways of scaling up our proposed intervention. Finally, we conclude from both our structural estimates - which take a rich set of other constraints into account - and our experimental findings that, in our context, providing pregnancy risk information has the potential to increase contraceptive use independently of other interventions targeting additional barriers

\footnotetext{
${ }^{11}$ For recent evidence on the effect of mistrust in the health system on health-seeking behaviors, see Martinez-Bravo and Stegmann (2019); Alsan and Wanamaker (2017).

${ }^{12}$ Women not only increase their intentions to use contraception after receiving our information message, in the case of women who hold baseline beliefs below the WHO benchmark their intentions to use contraception also respond to the same extent to their baseline beliefs and to their beliefs revisions (see p. 33).
} 
to use.

In the rest of the paper, we provide details about the context, data collection and surveyed women's characteristics (Section 2), describe the beliefs data (Section 3) and present the model and estimation approach (Section 4), before reporting our model estimates and policy counterfactuals (Section 5) and experimental results (Section 6). Section 7 concludes.

\section{Context, Data Collection and Respondents' Characteristics}

\subsection{Context}

With a GDP per capita of only US \$426 per capita in 2017, Mozambique remains one of the poorest countries in the world despite recently experiencing 20 years of rapid economic growth (1996-2015). Fertility is just above the average in Sub-Saharan Africa (SSA) (of 4.8 children per woman), and has been decreasing only slowly: the total fertility rate (TFR) was 5.9 in 1996, and it had only declined to 5.2 by 2017. As of 2015, 23.1\% of married Mozambican women aged 15-49 had an "unmet need for contraception" (SSA average: $24.1 \%$ in 2014), and $25.3 \%$ used a modern contraceptive method compared to a SSA average of $26.3 \%$ (in 2014). ${ }^{13}$

Within Mozambique, there is substantial heterogeneity in the TFR across provinces, which mirrors economic inequalities. In the three provinces in the south of the country in which we collected the data used in this paper, it ranges from 2.5 children per woman in the capital city Maputo to 3.4 in Maputo Province, and 4.7 in Gaza. In the Northern province of Niassa, it is as high as 6.6. Contraceptive prevalence is about twice as high in the south as in the north - ranging from $42 \%$ to $47 \%$ in the three provinces that we study in the south (similar to Kenya or Malawi in 2010) to only $18-22 \%$ in the northern provinces. Nonetheless, the share of married women aged 15-49 with an unmet need is still between 17\% (Maputo

\footnotetext{
${ }^{13}$ All figures reported in this section up to this point are taken from World Development Indicators (2019). SSA refers to SSA excluding high-income countries. The figures for Mozambique reported in the rest of this subsection are taken from MISAU, INE and ICF (2016).
} 
City) and 25\% (Maputo Province) in the south, roughly comparable to rates in the north (19\% in Nampula and 30\% in Zambézia).

\subsection{Data Collection}

In keeping with the focus of our research - namely the causes of the gap between women's fertility intentions and contraceptive use - we only collected data from women who state that they do not want to become pregnant at least in the coming two years (following the Demographic and Health Surveys' cutoff) and who were likely to need contraception to achieve their fertility intention.

More specifically, we used a screening questionnaire to identify women who: (1) were between 18 and 49, (2) were currently married or living maritally, (3) whose husband or partner, if working away, normally returned home at least once per month, (4) did not identify as infecund when asked about their pregnancy intentions, (5) were not pregnant, (6) did not want any more children or wanted more but did not want to become pregnant in the coming two years and (7) when asked how likely they would be to state the same fertility intentions if the enumerator came one month later and asked them the same question, answered that they would either "certainly" or "probably" give the same answers. ${ }^{14}$

The survey collected data across nine districts of three provinces in Southern Mozambique (Maputo city, Maputo province and Gaza province). In order to ensure a fairly representative mix of socioeconomic categories, we selected districts of different socioeconomic levels and the door-to-door recruitment of respondents was guided by targets for the distribution of women's level of education based on the proportions of women with an "unmet need" for FP found in each province in the latest available Demographic and Health Survey (DHS) at the time of fieldwork (DHS 2011) - the targeted proportions were achieved within a maximum 3 percentage points (\%-points) margin of error.

Fieldwork took place between January 18 and February 16, 2018. The probabilistic beliefs survey instrument followed best practices in the area (Delavande et al., 2011; Delavande and Kohler, 2012). In particular, we used visual aids, so that

\footnotetext{
${ }^{14} 86 \%$ (14\%) of women selected for the full interview answered that they would certainly (probably) state the same fertility intentions.
} 
respondents are asked to express their probabilistic beliefs by choosing the number of dried beans to be placed on a grid of 20 cells, where 0 means that the respondent is certain that an event will not occur while 20 beans mean that the respondent is certain that the event will occur. ${ }^{15}$ We started with a short training module based on Delavande and Kohler (2012), in which respondents were introduced to the visual aids and asked a few training questions about events they are familiar with such as the probability that they will go to the market in the coming 2 days/2 weeks, creating opportunities for the respondents to receive feedback on the consistency of their responses. After these training questions, the respondent was given a chance to ask questions if she had any. After answering these, the enumerator started the module about beliefs related to contraception, and from then on did not comment anymore on the respondent's answers.

We first asked women about their demographic characteristics, socioeconomic status (SES), fertility history, and about the contraceptive methods they knew of, using the same wording as in the DHS wherever possible. ${ }^{16}$ For all the methods (modern or "traditional") that the respondent said they knew of, as well as for the "no method" alternative, we elicited women's probabilistic beliefs about all the main factors which previous literature has suggested may matter in the decision to use a contraceptive method. We asked about the expected direct costs and indirect costs (e.g., transport costs) of using each method they knew of, as well as about their expected chance of: pregnancy within 12 months, contracting an STD within 12 months, experiencing nausea or headaches, experiencing menstrual irregularities or vaginal infections, experiencing "other" side effects, alteration of (their or their partner's) libido or sexual pleasure or interference with romance, getting pregnant within 12 months of discontinuation if wanting to get pregnant, obtaining the method when needed, approval by their partner, their partner finding out that they are using the method - or not using the method in the case of the "no method" method. ${ }^{17}$

\footnotetext{
${ }^{15}$ Based on evidence presented in Delavande et al. (2011), we asked respondents to express their answers out of 20 rather than out of 10 to improve precision.

${ }^{16}$ In particular, we followed the DHS tried and tested method to identify women's knowledge of contraceptive methods, prompting women with a brief description whenever they did not immediately said they knew of a method.

${ }^{17} \mathrm{We}$ also asked about the mode of administration of each method, but this question does not
} 
After eliciting women's probabilistic beliefs about contraception, we also asked, among others, about their intentions to use contraception in the future (following the DHS wording of "Do you intend to use a method to postpone or prevent getting pregnant, at some point in the future? Yes/No/Don't know"), about their partner's desired fertility, and about their sexual activity in the previous- and previous three months.

We obtained data from 651 women. Of these women, 20 are not sexually active (i.e., report not having had sex in the previous three months) and 24 qualify as infecund based on the DHS definition, and so we drop them from the sample. ${ }^{18}$ We also drop 23 women who say they use FP strategies other than the five main options we consider: injections, no family planning, contraceptive pill, implants and male condoms. ${ }^{19}$ Out of the 584 women in the resulting analytical sample, 14 women use a combination of methods (i.e., some combination of condom and hormonal method, except for one case combining the pill and implants). In the 13 cases combining a hormonal method with male condoms, we assign the woman to the hormonal method under the assumption that, in these cases, condoms are used mainly for protection against STDs rather than family planning. In the remaining case in which the pill and implants are combined, we assign the woman to implants as it is the most effective of the two methods and it seems likely that the pill was prescribed in order to combat the implants' side effects such as to regulate bleeding.

\subsection{Respondents' Characteristics}

In Panel A of Table 1, we report demographic and socioeconomic characteristics of the women in our analytical sample. These women have, on average, 2.6 children

appear to have been well understood by respondents, e.g., with a number of women saying that the mode of administration of male condoms is "oral". We also asked about the expected probability of weight changes if switching to each method from the woman's current method. But since we do not model method changes, answers to these questions may be misleading and so we do not use these variables.

${ }^{18}$ I.e., they started living maritally five or more years before the interview, are not currently using and have never used contraception, but have not had a child in the past five years and are not pregnant.

${ }^{19}$ This amounts to dropping 3 women using non-modern methods (periodical abstinence and coitus interruptus), 10 women using an intrauterine device and 7 women who are sterilized. The number of women using each of these methods is too limited to allow estimation. 
and are 29.1 years old, and in most cases either have some primary schooling (44\%) or some secondary schooling (42\%).

In Panel B, we report key descriptive statistics regarding contraception. On average, women know about more than four contraceptive methods, and nearly three (2.73) out of the four main methods analysed here (injections, implants, pill and male condoms). While all the women in our sample say - as per our sample selection criteria - that they do not want to get pregnant (at least in the coming two years), 30\% are not using any contraceptive method. The most popular contraceptive method is injections, followed by the pill, implants and male condoms.

Among the $30 \%$ who are not using contraceptives, 6 percentage points are due to women whose period has not returned yet since their last child was born. These women do not, however, report using lactational amenorrhea (LAM) as a contraceptive method, and so we classify them as choosing the "no method" alternative. Somewhat surprisingly, there is a general lack of knowledge about LAM in the study area. Only 6 out of the 584 women in the sample say that they have heard of LAM as having a protective effect against pregnancy (even after it was explained to them in plain terms using the DHS descriptor). ${ }^{20}$ This lack of knowledge about LAM was confirmed in focus group interviews carried out with women outside our survey sample who also want to limit or delay fertility. ${ }^{21}$

In $30 \%$ of cases, women report that their partners have higher fertility preferences than them. ${ }^{22}$ There is however only limited correlation between not using a method and having a partner who has higher fertility preferences. Table A-1 splits

\footnotetext{
${ }^{20}$ The DHS description for LAM is: "After giving birth, you would be protected from getting pregnant as long as you breastfeed frequently until your menstruation returns.".

${ }^{21}$ Out of 10 focus groups, the probability of pregnancy whilst breastfeeding was discussed 8 times. In each case, it was spontaneously mentioned by women in the context of being at risk of unintended pregnancy (almost immediately after birth) if not using another contraceptive method. Only one woman across all focus groups mentioned that breastfeeding might reduce the risk of pregnancy. In the two focus groups in which the moderator directly asked women whether they knew of LAM (using the DHS descriptor), the response was that they did not know, and women expressed surprise at the idea that breastfeeding, even in the first six months, may protect against pregnancy.

${ }^{22}$ More precisely, $30 \%$ of respondents answer "yes" when asked, towards the end of the interview, whether her partner wants to have more children (if the respondent said she did not want anymore) or whether her partner wants to have a child sooner than her (if she said that she wanted to have another child, but wanted to wait at least 2 years).
} 
the sample according to whether the woman's partner has higher fertility preferences, and shows that a larger share of women are not using contraception when their partners have higher fertility preferences (37\%), but that the rate of women not using FP is still high among women whose partners have similar fertility preferences (27\%).

In Table A-2, we compare key characteristics of women in our sample (Col. 1) with two representative samples. Col. 2 reports summary statistics for cohabiting women age 18 and above who say they do not want to get pregnant in the coming two years interviewed in the 2015 AIDS Indicator Survey (AIS) in the same three provinces, while Col. 3 reports summary statistics for women with the same characteristics for the whole AIS 2015 survey. The women in our sample tend to be younger. At least in part because of this, on average they have fewer children than their counterparts in the AIS and are also more likely to have secondary education and above. They are less likely to report not using contraception (30\% vs. 38\% in the same three provinces in the 2015 AIS), and more likely to use long acting reversible contraceptives ("LARC", here specifically injections and implants). A comparison of Columns (2) and (3) confirms that the three provinces we targeted have higher levels of economic development than the rest of country as well as lower levels of unmet need for contraception conditional on not wanting to get pregnant within two years.

\section{Beliefs Data}

\subsection{Data Validity}

In order to check the extent to which respondents understand the concept of probability - although the word "probability" was not used in the interviews, we asked respondents to show the enumerator the number of dried beans (out of 20) that best reflected their probability of getting pregnant in the coming year, and then in the coming 5 years. Under $8 \%$ of women responded a larger probability in the coming year than in the coming 5 years at their first attempt. After the enumerator explained to these women that she expected a response indicating a larger probabil- 
ity in the coming 5 years than in the coming year as she would have 4 more years, $5 \%$ of women still give a lower probability of getting pregnant within 5 than within 1 year. In a robustness check, we exclude these women from the sample and find similar results.

We also asked women to tell us, for four different months in the calendar year (April 2018, July 2018, October 2018, and January 2019), the number of beans which best reflected the probability that it would rain in any given day during this month. While in the years prior to the survey there was much year-on-year variability in the number of rainy days in April and July, women should know that January is the peak of the rainy season while October is a reliably mostly dry month. ${ }^{23}$

Figure A-1 shows the distribution of the difference between the expected probability of rain in any given day in January and October. The average difference in answers for the two months is 3.6 beans, compared to an actual difference - expressed in 5-percentage point beans - of 6.2 (3.7) between 2015 and 2017 (2009 and 2018). This suggests that women understood the survey instruments well and that we were able to elicit their probabilistic beliefs reliably.

\subsection{Descriptive Statistics}

Table 2 reports selected probabilistic beliefs statistics where answers out of 20 dried beans are converted in probabilities (out of 1) for convenience. ${ }^{24}$

The women in our sample appear to have a very good knowledge of the risk of pregnancy when using condoms. They report this risk to be $17 \%$ on average, which is nearly identical to the $18 \%$ pregnancy risk under typical use reported by the WHO. ${ }^{25}$ Their average expected probability of pregnancy when using no method is high $(78 \%)$, but it is lower than the risk in the general population of sexually active women according to the WHO (85\%). While it is not possible to say exactly what the true risk of pregnancy is for the women in our sample under each method,

\footnotetext{
${ }^{23}$ The number of rainy days by month between 2015 and 2017 is: 9 to 16 in April, 2 to 13 in July, 16 to 19 in January and 7 to 8 in October (https://www.worldweatheronline.com/maputo-weather-averages/maputo/mz.aspx).

${ }^{24}$ Descriptive statistics for the other probabilistic beliefs can be found in Table A-3.

${ }^{25}$ See WHO/RHR and CCP, Knowledge for Health Project (2018).
} 
the risk incurred when using methods such as injections and implants, for which there is no variability coming from user's adherence to instructions, should be close to the WHO guidelines. Given this, they appear to vastly overestimate the risk of contraceptive failure associated with hormonal methods, from a factor of 3.1 for injections to as much as 4.9 for implants (and 3.9 for the pill).

Respondents have a very high expected unprotected probability of contracting an STD in the coming 12 months, and a good understanding of the fact that condoms, and condoms only, protect against STDs.

As in many other developing countries today, family planning is available free of charge in government facilities in Mozambique, and are also available at a cost from private providers. Consistent with the fact that, except for male condoms, at least $85 \%$ of users in the last DHS (2011) obtained their contraceptives from public providers, expected costs are low (from 14 to 27 Meticais per month or an annual cost of no more than $1 \%$ of GDP per capita).

Monthly indirect costs such as transport costs associated with each method vary from 23 (condom) and 37 (injections) Meticais per month, and the ranking of method by costs reflects what would be expected given the accessibility and frequency of administration of each method. ${ }^{26}$

Other variables related to supply also reflect the relative ease with which modern FP methods can be obtained, with an average expected waiting time of 19 (condoms) to 23 (injections and implants) minutes and an expected probability of being able to obtain the method when needed of $82 \%$ (implants) to $90 \%$ (condoms).

The women interviewed hold plausible beliefs regarding the probability of side effects. First, they understand that the risk of side effects is very low with condoms, but that hormonal methods come with a risk of nausea/vomiting, menstrual irregularities, and other side effects. It is difficult to compare the reported probabilities with an "objective" measure, but the range of values appears reasonable (from around 20\% for nausea (injections) to 58\% for menstrual irregularities (injections))

\footnotetext{
${ }^{26}$ In particular, the indirect cost of the pill and condoms, which are obtained from a range of providers including pharmacies, is lower than that of injections, which are overwhelmingly obtained from public health posts (MISAU, INE and ICF, 2013) and the indirect cost of obtaining implants, which are also obtained from a restricted range of providers, is lower than the indirect cost of obtaining injections, as would be expected by the difference in frequency of application.
} 
in light of reliable information stating that these and other side effects are "common to very common" for each of the three hormonal methods covered here (e.g., https://bnf.nice.org.uk).

Interestingly, on average women also hold reasonable beliefs about the effect of contraceptive methods on the ability to conceive after discontinuation. The average expected probability of managing to conceive in the 12 months following discontinuation if they decided that they wanted to get pregnant is $69 \%$ for implants and injections, $73 \%$ for the pill and $81 \%$ for condoms, compared to a $75 \%$ expected probability of managing to conceive within the coming 12 months if they decided that they wanted to get pregnant and were not currently using any contraceptive. In this sample, there is therefore no evidence of the mistaken belief that modern contraception has long-term effects on the ability to conceive.

We also elicited women's expected probability of approval of each alternative contraceptive method by their coreligionists (i.e., those in the same religion), as well as their parents, friends and partner. The women's expected probability of approval by others is generally low (60\% or less), especially in the case of coreligionists. It is important to note, however, that the women's expected probability of approval by partners if they did not use any method is even lower - $40 \%$ on average. This suggests caution in interpreting the low levels of expected approval of use of contraceptives as a sign of disapproval of contraceptive methods rather than a sign that the women's social circle is not very supportive in general. As would be expected, women who say that their partners want more children or want them earlier than them have a lower expected probability that their partners would approve of them using a method relative to not using a method. ${ }^{27}$

Women's answers to questions about the probability of being able to hide from their partner the use of each method or non-use of any method are also plausible. Reassuringly, the vast majority of respondents do not think they would be able to use male condoms without the knowledge of their partners. For the other methods and for using no method, the expected probability of being able to hide use or

\footnotetext{
${ }^{27}$ For instance, the expected probability of approval if using injections minus the expected probability of approval if not using any method is 25 (2) \%-points on average among women whose partners have similar (higher) fertility preferences.
} 
non-use from partners varies between $32 \%$ (implants and doing nothing) and $42 \%$ (injections). This suggests that women took into consideration the fact that men can infer the use or non-use of contraception based not only on the direct observation of use of the method but also from side effects such as menstrual irregularities and pregnancy (non-)occurrences.

In summary, women in our sample are, on average, well informed about the failure rate of the male condom method, but underestimate somewhat the probability of pregnancy when not using any contraception and vastly overestimate (by a factor of between about 3 and 5) the probability of pregnancy when using hormonal methods - resulting in a large underestimation of the ability of hormonal methods to protect women against pregnancy relative to using no method. Women also understand perfectly well that only condoms protect against STDs, and have a high expected risk of contracting STDs when using no protection. Expected monthly costs, waiting times and other issues with supply are low. The expected probability of side effects is high (and within a reasonable range). Finally, expected rates of approval by others are low for any action that the women could take including using no method.

Another important characteristic of these subjective beliefs data is their dispersion, even within groups defined by socioeconomic status and demographic characteristics. If every woman with similar observable characteristics held the same beliefs, then there would be no need to collect subjective beliefs data in order to identify their preferences for different aspects of family planning - population averages (e.g., on the chance of pregnancy within 12 months for given observable characteristics) would suffice. This is however not the case. There is indeed much variation in beliefs, as illustrated by the standard deviations reported in Table A-3. This is true even within demographic/SES group. For instance, the expected probability of pregnancy within 12 months varies much within age group, as shown in Figure A-2.

In the next section, we use our rare beliefs data in order to identify women's preferences regarding the wide range of contraceptive characteristics about which we elicited beliefs and predict the effect of several candidate policies on contraceptive use. 


\section{Model and Estimation}

The idea of our modelling exercise is that women choose the alternative (no method, injections, pill, condoms or implants) associated with the highest utility when taking into account all the expected consequences of choosing each method in their choice set. The combination of the contraceptive choice they make and their beliefs about the consequences of this choice provides information about how much they care about each of the perceived characteristics of each method.

For illustration, consider the distribution of beliefs for each potential method (rows) by method used (columns) (Table 3). Except for women using no method, for whom the highest expected level of partner approval would be achieved by using condoms, the method chosen is the one with the highest average expected rate of approval by partners. There is therefore a strong correlation between the perceived likelihood of partner approval and a woman's current method. If confirmed after controlling for women's method-invariant characteristics - including whether their partner wants more children or wants them earlier - and beliefs about the many other aspects of contraceptive methods, this would indicate that women have a strong preference for method approval by their partners.

Similarly, we can compare, for each method used, women's expected risk of pregnancy within 12 months (Table 4). On average, women do not systematically choose the method they believe to have the lowest pregnancy risk. On the other hand, compared to women using contraceptive methods, women who do not use any method also have the lowest expected risk of pregnancy when not using any method. Without controlling for other women's characteristics and perceived methods attributes, however, it is difficult to say how much utility women derive from a reduction in the risk of pregnancy.

In order to shed light on women's preferences, we estimate an additive random utility model (ARUM) consistent with utility maximization. Formally, we start by modeling women as maximizing the following utility function:

$$
\max _{m \in M_{i}}\left\{\sum_{j=1}^{J} \int u_{j}\left(e_{j}, z_{i}\right) d P_{i m}\left(e_{j}\right)+\beta_{m}^{\top} z_{i}+\alpha E_{i}\left(c_{m}\right)+\varepsilon_{i m}\right\},
$$


where $m$ corresponds to the contraception method and the index set $M_{i}$ is woman $i$ 's choice set (i.e., the methods they know of). The index $j$ corresponds to the events for which we elicited beliefs in our survey (e.g., pregnancy within 12 months, contracting an STD within 12 months, ..., listed p. 10). Each one of these possible events is represented by a binary random variable $e_{j}, j=1, \ldots, J$, recording whether the woman gets pregnant within 12 months, contracts an STD within 12 months, etc. The function $u_{j}$ is the utility or disutility derived from event $j$ happening and may also depend on $z_{i}$, a set of woman characteristics that do not vary by method. The perceived probability that the event $j$ happens depends in turn on the contraception method adopted and is denoted by $P_{i m}$. The method invariant characteristics $z_{i}$, encompassing, for example, age, education, ..., may also affect the utility for the method differentially through $\beta_{m}$. Finally, $E_{i}\left(c_{m}\right)$ is the subjective expected cost of using method $m$ by woman $i$ and $\varepsilon_{i m}$ is an idiosyncratic method $\times$ individual-specific random component of utility.

With binary events $e_{j}$ and data on the expected probability of event $e_{j}$ happening and on the expected cost of each method, the probability of choosing method $\bar{m}$ can be written as:

$$
\begin{aligned}
& \operatorname{Pr}\left(\bar{m} \mid z_{i},\left\{P_{i m}\left(e_{j}\right), E_{i}\left(c_{m}\right)\right\}_{j \in 1, \ldots, n}^{m \in M_{i}}, M_{i}\right) \\
& =\operatorname{Pr}\left(\sum_{j=1}^{J}\left[\Delta u_{j}\left(z_{i}\right) P_{i \bar{m}}\left(e_{j}=1\right)\right]+\beta_{\bar{m}}^{\top} z_{i}+\alpha E_{i}\left(c_{\bar{m}}\right)+\varepsilon_{i \bar{m}}>\right. \\
& \left.\sum_{j=1}^{J}\left[\Delta u_{j}\left(z_{i}\right) P_{i m}\left(e_{j}=1\right)\right]+\beta_{m}^{\top} z_{i}-\alpha E_{i}\left(c_{m}\right)+\varepsilon_{i m}, \forall m \in M_{i}, m \neq \bar{m}\right)
\end{aligned}
$$

where $\Delta u_{j}\left(z_{i}\right)=u_{j}\left(e_{j}=1, z_{i}\right)-u_{j}\left(e_{j}=0, z_{i}\right)$ is the difference in utility levels resulting from event $j$ happening rather than not happening. In the empirical implementation we model these $\Delta u_{j}\left(z_{i}\right)$ as $j$-specific parameters allowing for (linear) dependence on $z_{i}$ (namely, individual- and partner fertility preference measures) for specific $j$ s. Given data on woman $i$ 's subjective beliefs $P_{i m}\left(e_{j}=1\right)$ for every event category $j$ and each method $m$ in their choice set, expected methods costs $E_{i}\left(c_{m}\right)$ (e.g., waiting time, direct and other monetary costs) for every method and a distributional assumption on $\varepsilon_{i m}$, we can estimate Equation (1) and thus identify 
women's preferences $\left(\Delta u_{j}\right.$ and $\left.\alpha\right){ }^{28}$

If we assume that the $\varepsilon_{i m}$ are independent Type I extreme value random variables, then the probability of choosing $\bar{m}$ can be modeled as a logit. A limitation of the resulting conditional logit model is its implied independence of irrelevant alternatives (IIA): the relative choice probabilities for any two alternatives does not depend on characteristics of other methods. This assumption is unlikely to be satisfied for methods which share many similarities, which is the case for the three hormonal methods. We relax the IIA assumption by adopting instead a nested logit, in which women are thought of choosing between three independent top-level limbs (no method, condoms, or hormonal methods) as well as choosing between three bottom-level branches (injections, implants, or the pill) within hormonal methods as depicted in Figure 1. Consequently the random shocks affecting the choice between no method, condoms, or hormonal methods are assumed to be independent, but random shocks affecting the choice between different hormonal methods are allowed to be correlated Type I extreme value random variables (see Cardell, 1997).

In this nested logit model, we estimate (i) the effect of method-invariant variables on the choice of broad type of method (no method, condoms, or hormonal methods) using the variation between women in these variables (e.g., education level, desire to limit vs. desire to space fertility) and (ii) the effect of methodspecific variables (e.g., expected monetary cost) using only the variation in beliefs within woman between methods. The logit specification implies that any womanspecific additive "fixed effect" affecting beliefs over a given characteristic of methods (e.g., over a given $e_{j}=1$ and/or over $E_{i}\left(c_{m}\right)$ ) is "factored-out" as long as it applies to all methods. ${ }^{29}$ For instance, if a woman systematically overestimates or overstates her expected monetary cost irrespective of the method used, this ten-

\footnotetext{
${ }^{28}$ We use a subjective expected utility maximization approach, assuming that the precision of beliefs does not affect the decision process. Taking the precision of beliefs into account would require data on the dispersion of beliefs and thus add substantially to an already long survey. It would also require making assumptions about how this precision enters the utility function. While we did not collect these data, the good level of understanding of the beliefs survey instruments by respondents suggests that it would be feasible, in future work, to elicit more complex beliefs potentially involving uncertainty or ambiguity regarding the beliefs.

${ }^{29}$ More specifically, denoting $P_{i 1 m}$ the subjective probability which woman $i$ associates with event $e_{1}=1$ when using method $m$, then adding $\alpha_{i}$ to $P_{i 1 m}$ for all methods $m$ is cancelled out in pairwise comparisons.
} 
dency to overestimate expected monetary cost could be systematically correlated with the choice of method without leading to bias in our estimates.

\section{Estimation Results and Policy Counterfactuals}

\subsection{Estimation Results}

In Table 5, we report nested logit estimates for coefficients on some of our main variables. Full results are reported in Table A-4.

The models in Columns (1) to (4) include all the method-invariant variables such as woman's age group and method-specific variables - e.g., perceived probability of pregnancy with the index method - listed in Tables 1 (Panel A) and A-3 respectively. As explained below, we allow for heterogeneity in preferences for three method-specific variables by interacting them with individual- and partner fertility preference variables.

Our sample comprises two groups: women who simply want to space fertility - i.e., they want to have a(nother) child after two years - and those who want to limit fertility - i.e., they do not want another child in the future. Women who want to limit fertility may care more about the ability of a method to protect them against pregnancy than women who simply want to space fertility. Similarly, women who want to have children in the future may care more about the ability to resume fertility after discontinuation of the method. We therefore model $\Delta u_{j}\left(z_{i}\right)$ as a linear function of $z_{i}$ where $j$ is, in turn: (1) the pregnancy risk and (2) the probability of managing to get pregnant within 12 months of discontinuation and $z_{i}$ is, in turn, an indicator for having (i) a "need for spacing" or (ii) a "need for limiting" fertility. ${ }^{30}$

Women may also value more the ability to conceal the use of a method from their partner if their partners disagree with their fertility intentions. Thus we also interact the subjective probability of being able to hide the use of the method from her partner with whether the woman's partner has or not higher fertility preferences. ${ }^{31}$ In other words, we also model $\Delta u_{j}\left(z_{i}\right)$ as a linear function of $z_{i}$ where $j$ is

\footnotetext{
${ }^{30}$ Note that we do not include a constant in this linear function as the two categories "need for spacing" and "need for limiting" exhaust all the possibilities given our sample selection criteria.

${ }^{31}$ I.e., whether she thinks or not that her partner wants more children (if she does not want to
} 
the "probability of hiding the method" and $z_{i}$ is, in turn, an indicator for having a partner who (i) has or (ii) does not have higher fertility preferences.

The difference between the first four columns of Table 5 stems from the sample used. In Column (1), missing values about method-specific characteristics are set to zero and we include one binary variable per method-specific belief indicating missing values. In Column (2), we repeat the same specification on the sample of observations for which women did not answer, at most, three out of the 16 questions used to create the method-specific variables. While we only elicited beliefs about methods which the respondent reported knowledge of, the aim of this exercise is to address the possibility that women may know of methods that are not genuinely in their consideration set and for which they therefore only have limited information. In Column (3), we repeat the same specification as in Column (1), dropping this time the 28 women who answered a higher probability of getting pregnant within the next 12 months than within the next 5 years in the training questionnaire module. In Column (4), we do not impute missing values.

Starting with Columns (1) to (3), we find that women who want to limit fertility are marginally less likely to choose an alternative associated with a higher risk of pregnancy (p-value: 0.105 in Column (1)), but that this is not the case for women who simply want to delay their next pregnancy.

Women also respond to their expected probability of experiencing side-effects: they are less likely to use methods associated with higher risks of nausea/vomiting, less likely to use methods associated with side effects not listed in our questions ("other negative effects"), but more likely to choose methods associated with menstrual irregularities - presumably because they value not having their periods or having lighter periods.

The strongest explanatory factor in choosing an alternative is however a woman's expected probability that her partner would approve of the alternative. Recall that these estimates are net of the effect of the method-invariant variables listed in Table 1 (Panel A) including whether the woman's partner has higher fertility preferences than her. Therefore, here we find that a woman's expected approval have any more) or wants another child sooner than her (if she simply wants to delay for at least 2 years). 
by her partner is a key factor in her choice of FP strategy even after conditioning on disagreement between partners about fertility targets. Interestingly, women whose partners have similar fertility desires to themselves are significantly less likely to opt for more concealable FP approaches, whereas concealability has no effect on method choice for women whose partners have higher fertility desires. This suggests that women have a distaste for concealability - consistent with Ashraf et al. (2014)'s finding that using concealable methods has a psychological cost — but that they are willing to incur this utility cost when their partners do not want them to use contraception.

There is also much to learn from characteristics which do not appear to matter in women's choices. Strikingly, women do not choose methods associated with a lower risk of contracting STDs, suggesting that the decision to use protection against STDs studied, e.g., in Cassidy et al. (2020), may be largely independent from that of using contraception in the setting we examine. ${ }^{32}$ The expected probability of reduced libido and/or sexual pleasure of either partner and/or interference with romance does not appear to affect contraceptive choices.

In stark contrast with expected approval by her partner, expected approval by coreligionists, parents, or friends do not have any significant effect on the woman's choice of method, which points towards the importance of communication and/or bargaining between partners as opposed to fundamental religious or cultural barriers to contraceptive use.

None of the supply-side factors are consistently statistically significant except for expected costs of travel and other indirect costs, which have a negative effect on demand. When we drop the 28 women who understood less well our beliefs training questions, a higher probability of obtaining the method when needed significantly increases demand while women appear significantly more likely to use methods associated with a higher direct expected cost of obtaining the method. We cannot

\footnotetext{
${ }^{32}$ Cassidy et al. (2020) analyse the effect of introducing an additional condom technology female condoms - on the couple's bargaining over condom use. To do so, they randomize the timing of exposure to an intensive intervention carried out in a Maputo slum in which (just under 300 ) enrolled women took part, over a period of 3 months, in fortnightly meetings promoting the use of female condoms through discussions about a range of sexual and reproductive issues, from HIV to consent, negotiation of contraceptive use, intimate partner violence and womens rights.
} 
rule out that contraception is a Giffen good, but given evidence of the high elasticity of demand for preventive health products in Sub-Saharan Africa (Dupas, 2011) a more plausible explanation may be that, despite our comprehensive data collection exercise, this variable proxies for some unobservable attributes of contraceptive methods that increase the utility women derive from methods that they expect to obtain from the private sector - and therefore pay for - such as the cleanliness of the facilities or the quality of the staff or more flexibility in the appointment schedule.

Turning now to the effect of method-invariant variables, we find that older women, women whose partners have higher fertility preferences, atheists and, in the case of Column (3), protestants, are more likely to use no method relative to their likelihood of using a hormonal method, while women who do not want any more children are less likely to use no method. Women who have more children are less likely to use condoms relative to their likelihood of using hormonal methods. Belonging to a small religious category (accounting for $3 \%$ of the sample or less) also affects the probability of using condoms: women who say they "do not know" what their religion is or refuse to answer the question about religious affiliation are more likely to use condoms while Protestants are less likely to.

As can be seen by comparing the first three columns of Table 5, other than for the effect of expected costs, results are robust to (i) excluding methods which may not genuinely belong to the woman's consideration set, operationalized here as methods for which a woman answered fewer than 13 out of the 16 questions used to construct our method-specific variables (Column 2) and (ii) excluding the 28 women who are likely to have provided less reliable answers to our beliefs questions given their inconsistency when answering the training questions about the chance that they would get pregnant within 12 months and 5 years of the interview (Column 3).

In Column (4), we show estimates obtained when using only the woman $\times$ method observations for which there is no missing answer to any of the 16 method-specific questions we used to create the method-specific dependent variables. $^{33}$ Doing so results in losing 993 woman $\times$ method observations relative to

\footnotetext{
${ }^{33}$ Results obtained when excluding cases (women) with any missing value for any variable in-
} 
the baseline model of Column (1). The pattern of non-response also appears to be non-random, with younger, better educated women and women whose partners have higher fertility preferences than themselves being significantly more likely to answer all the questions.

Results using the sample of observations without any missing values are qualitatively largely similar to those obtained in Columns (1) to (3), but they are less precisely estimated and some estimated effects are also smaller in magnitude and become insignificant. ${ }^{34}$ This is, for instance, the case for the effect of the expected probability of getting pregnant within 12 months for women who do not want any more children. In the baseline model of Column (1), the effect is equal to -0.013 with a standard deviation of 0.0079. In Column (4), the effect (SD) becomes -0.008 (0.0083). In order to shed light on the extent to which this difference is due to sample selection, we compare two sets of estimates from a model controlling only for method-invariant characteristics and the method-specific expected probability of pregnancy variables and which we can therefore estimate both on the full sample of women answering the pregnancy risk question (Column 5) and on the sample of women answering all method-specific questions (Column 6). The results indeed suggest sample selection on preferences for a method's efficacy in preventing pregnancy in the restricted sample results of Column (4), since the magnitude of the coefficient is reduced by $39 \%$ when going from Column (5) to Column (6), which is very similar to the $44 \%$ decrease in the magnitude of this coefficient when going from Column (1) to Column (4).

Finally, we explore the possibility that the perceived risks of pregnancy and of contracting an STD matter in a woman's FP decisions specifically when choosing between the top branches of her decision tree - i.e., when choosing between

stead of deleting only the alternatives (woman $\times$ method observations) with missing values are qualitatively similar. Two differences in significance levels are that, as in Column (3), the effect of expected probability of obtaining the method when needed and the expected direct costs of the method have significant (positive) effects on method choice.

${ }^{34}$ In the linear regression model, there is a trade-off between potential biases arising from the use of indicators to account for missing values when missingness is related to covariates as suggested above and the loss of precision resulting from the exclusion of observations with missing values (see Jones, 1996). Reassuringly, the experimental findings reported in Section 6 corroborate our estimates, which suggests that these biases are small in the present analysis. 
using no method at all or a hormonal method or condoms. In Column (7), we control for beliefs about fecundity - i.e., the woman's expected probability of getting pregnant within 12 months when using no contraception - and beliefs about exposure to STDs - i.e., the woman's expected probability of contracting an STD within 12 months when using no contraception. In doing so, we exploit the variation between women in beliefs about fecundity without contraception and exposure to STDs rather than variation within woman between methods. We find that women who believe to be at a higher risk of pregnancy when using no contraception are very significantly less likely to use no contraception (and somewhat less likely to use condoms relative to hormonal methods) but that perceived exposure to STDs has no impact. ${ }^{35}$

The signs of the nested logit coefficients show the direction of their effect on the probability of choosing each alternative. And provided the regressors are measured in the same unit (e.g., probability of pregnancy out of 20 and probability of nausea/vomiting out of 20), the magnitude of the coefficients reflects the relative importance of each method characteristic in the choice of method. Selected average partial effects are reported in Table A-5 to illustrate the economic significance of the point estimates. We report own- and cross-partial effects on the probabilities of choosing no method and choosing the most popular method (injections) for a range of variables. Expressing the effects of small deviations in terms of a oneunit change, a one-bean (5\%-point) increase in the probability of pregnancy absent contraception corresponds to a negative average partial effect on the probability of choosing no method of $1.1 \%$-points, and about half of this decrease translates into a positive average partial effect on the use of injections. Even considering the type of side effect with the largest nested logit coefficient ("other negative effects"), a one-bean (5\%-point) decrease in the probability of injections side effects only produces a negative $0.1 \%$-point partial effect on non-use. A one-bean (5\%-point) increase in the probability of the partner approving of injections leads to a $3.4 \%$ point partial effect on the use of injections, but most of this increase comes from

\footnotetext{
${ }^{35}$ When estimating separately the effect of beliefs about fecundity for women with a need for spacing- and a need for limiting fertility, we find negative and significant effects on the probability of not using contraception for both groups, and these are larger for women with a need for limiting(-0.091, standard error: 0.035$)$ than for spacing pregnancy (-0.053, standard error: 0.028$)$.
} 
substitution away from other methods, with a negative partial effect on non-use of only $0.43 \%$-point. The effect of increasing the indirect cost of using injections by one unit (Metical) is small, as the partial effect on the demand for injections is only negative $0.04 \%$-point. If we went from none- to all the women's partners having higher fertility desires than them, non-use would increase by $8.8 \%$-points and demand for injections would decrease by $3.6 \%$-points. This is not dissimilar to the effect of going from all women wanting to limit fertility to simply wanting to space it (11\%-points and 3.2\%-points, respectively).

In Section 5.2, we present a number of policy counterfactuals which illustrate further the absolute- and relative importance of different barriers to contraceptive use.

\subsection{Policy Counterfactuals}

We now turn to predicting the effect of alternative interventions on the method mix using estimates from our preferred specification (Column 7 of Table 5). ${ }^{36}$

We consider the effect of seven alternative interventions on the predicted probabilities of using each of the five FP strategies considered in our estimation. Results are reported in Table 6. For conciseness, here we only discuss the effect on the predicted probability of not using any method.

First, we estimate the effect of increasing by $25 \%$-pts the expected risk of pregnancy absent contraception for women who have a baseline expected probability under $85 \%$ (the WHO reference). This is estimated to increase contraceptive use by $4.9 \%$-points among this group of women or $1.9 \%$-pts overall. If instead we fully recalibrate the beliefs of women who expect a risk of pregnancy of under $85 \%$ in the

\footnotetext{
${ }^{36}$ The choice probability for option $\bar{m}$ is given by $\operatorname{Pr}\left(\bar{m} \mid z_{i},\left\{P_{i m}\left(e_{j}\right), E_{i}\left(c_{m}\right)\right\}_{j \in 1, \ldots, n}^{m \in M_{i}}, M_{i}\right)=$ $\frac{\exp \left(V_{\bar{m}} / \tau(\bar{m})\right)}{\exp (\operatorname{IV}(\bar{m}))} \frac{\exp (\tau(\bar{m}) \operatorname{IV}(\bar{m}))}{\sum_{n} \exp \left(\tau_{n} \mathrm{IV}_{n}\right)}$. The variable $V_{\bar{m}}$ denotes $\sum_{j=1}^{J}\left[\Delta u_{j}\left(z_{i}\right) P_{i \bar{m}}\left(e_{j}=1\right)\right]+\beta_{\bar{m}}^{\top} z_{i}-\alpha E_{i}\left(c_{\bar{m}}\right) . \operatorname{IV}_{n}$ denotes the "inclusive value" (i.e., expected utility) for nest $n$ and is given by $\ln \left(\sum_{m \in B_{n}} \exp \left(V_{m} / \tau_{n}\right)\right)$, where $B_{n}$ is the set of alternatives in nest $n$ and $1-\tau_{n}^{2}$ is the correlation among alternatives in nest $n$. For limbs with only one alternative, like those for condoms and no method, $\tau$ is one. We estimate $\tau$ in the hormonal nest to be between 0.2 and 0.5 depending on our specification (see Table A-4). The notation $\operatorname{IV}(\bar{m})$ and $\tau(\bar{m})$ corresponds to the inclusive value and $\tau$ for the nest to which alternative $\bar{m}$ belongs. These expressions are used to generate the predicted choice probabilities in our different counterfactual scenarios.
} 
absence of contraception to match the $\mathrm{WHO}$ reference rate of $85 \%$, contraceptive use would increase by about $2.7 \%$-points overall.

Increasing by $25 \%$-points the expected rate of approval by partners of all modern methods would increase contraceptive use by 3.6\%-points, while increasing this expected rate of approval to $100 \%$ would increase contraceptive use by $7.6 \%$-pts.

A major scientific breakthrough removing all side effects accompanied by a successful campaign convincing women of this progress would only increase contraceptive use by $0.3 \%$-points.

Removing all supply-side constraints - i.e., setting the expected probability of obtaining the method when needed to $100 \%$ and setting all costs and waiting times to zero - would reduce unmet need by $1.1 \%$-points.

These counterfactual scenarios broadly match the main reasons generally selfreported for not using any contraception despite not wanting to get pregnant (low perceived risk of pregnancy, side effects, disapproval by the women themselves or those close to them), and additionally consider the effect of removing all supplyside barriers.

Of these four approaches to reducing "unmet need" for family planning, two would likely be very costly (removing side effects and removing supply-side constraints). Our predictions indicate that they would also not be particularly effective, suggesting low cost-effectiveness.

Much more encouragingly, increasing perceived method approval by partners would be a powerful tool to decrease unmet need, thus suggesting a fruitful direction for future work. Similarly, we find that aligning the woman's partner's preferences for fertility with the woman's would increase contraceptive uptake by $2.4 \%$-points. The cost of increasing the rate of method approval by partners is however unclear a priori and may be very high if it is due to aversion to contraceptive methods deep-rooted in patriarchal social norms. Although decreasing men's fertility preferences is possible (see, e.g., Ashraf et al., 2018), doing so to the extent that they would match the women's is likely to be costly too.

Our policy counterfactuals however suggest that sizeable increases in contraceptive uptake would result from a potentially low-cost recalibration of women's beliefs about the risk of pregnancy absent contraception. In Section 6, we further 
investigate this possibility through an information experiment carried out at the end of the survey described in Section 2.

\subsection{Ex-post Rationalization}

One limitation of the policy counterfactuals of the previous section, as with any modelling exercise relying on observational data, is that confounding factors might bias estimates - although this risk is mitigated here by the collection of data covering a large array of factors that may influence contraceptive decisions and which would normally fall in the "unobservables" category.

In particular, one concern may be that women systematically report more favorable beliefs about the alternative they are currently using in order to justify their choices - i.e., they may practice "ex-post rationalization". 37 If this were the case, then this may bias the nested logit estimates so that our model predictions may not be informative regarding the effect of changing beliefs. Ex-post rationalization does not, however, seem likely to be an important issue in our data for two reasons.

First, women do not systematically report more favorable beliefs about the method they are currently using. For instance, women do not report a systematically lower risk of pregnancy for the contraceptive method they are currently using (Table 4).

Second, there is no evidence that women who have been using a contraceptive method for a longer period of time are more likely to report favorable beliefs about this method. As noted by Delavande and Zafar (forthcoming), ex-post rationalization should arguably be stronger among individuals who have been with their current alternative for a longer period of time - i.e., their chosen university in the case of Delavande and Zafar (forthcoming). However, in our data as in theirs, there is no indication that individuals who have been with their current alternative for a longer period of time report more favorable beliefs. Table A-6 reports estimates obtained when regressing each belief variable in turn on the year the woman

\footnotetext{
${ }^{37}$ Ex-post rationalization bias has previously been discussed in the context of fertility intentions — an area in which women may be thought to be particularly prone to ex-post rationalization since admitting that a child was unwanted may bear a high psychological cost. Pritchett (1994), however, finds that actual fertility is equally correlated with different measures of self-reported desired fertility, irrespective of whether the measure is retrospective, suggesting very low bias.
} 
started using the contraceptive method she is currently using, a constant, and all the method-invariant characteristics included in Panel A of Table 1. Only 2 out of 16 coefficients are statistically significant, and only marginally so. In one case (women who have started using the method more recently report higher probabilities of menstrual irregularities), the sign of the significant coefficient does not suggest ex-post rationalization. ${ }^{38}$ In the other (women who have started using the method more recently report higher expected waiting times), the magnitude of the effect is very small — starting use one year later increases the expected waiting time by less than 30 seconds.

More generally, the weakness of the correlation between stated beliefs and the duration of use of contraceptive methods also suggests that learning from use which could bias our estimates — is limited.

In the next section, we present experimental findings that corroborate our model estimates and hence bolster our confidence in these estimates.

\section{Experiment}

In order to test the plausibility of our model predictions, we created an experimental "shock" to beliefs about the probability of pregnancy absent contraception towards the end of the survey interviews. This allows us to evaluate - without making any modelling assumptions including the absence of ex-post rationalization or learning — the effect of a simple, easily-scalable information message on the perceived risk of pregnancy absent contraception and its effect on intentions to use contraception in the future. In addition, we compare the observed effect on intentions to use contraception in the future to the effect on contraceptive use which is predicted by our model based on the observed change in beliefs following our information message.

\footnotetext{
${ }^{38}$ Recall that the estimates reported in Table 5 indicate that women prefer methods associated with menstrual irregularities (e.g., because this generally means light or no periods).
} 


\subsection{Measurement and Information Treatment}

After eliciting the woman's beliefs about contraceptive methods, we asked her whether she intended to use contraception in the future (for the exact wording of the question, see p. 11).

We then asked a number of questions about the woman's (un-incentivized) willingness to pay for changes in four methods characteristics (efficacy in preventing pregnancy, observability by partner, reduction of side effects, and return to fecundity after discontinuation) and their level of trust in health information messages obtained from (nine) different potential sources. ${ }^{39,40}$

Next, we proceeded to our experiment. We selected a random subsample of women whom the enumerator informed that:

"Studies show that, on average, out of 20 sexually active women of reproductive age who do not use any contraception, 17 will get pregnant within the next 12 months"

The enumerator then asked the respondent again about their intention to use contraceptives in the future, as well as asking them again about the average expected probability of pregnancy within 12 months if not using any contraceptive for (i) women like her and then (ii) for herself.

We did not treat all the women in our sample to allow the possibility of measuring additional outcomes in follow-up surveys. ${ }^{41}$ The experimental variation exploited in the present analysis is the difference between answers given by the same

\footnotetext{
${ }^{39}$ More precisely, we asked the woman about her willingness to pay (WTP) for a method associated with a "zero bean" versus a "three bean" chance of, in turn: getting pregnant, being discovered by her partner, experiencing side effects, being unable to conceive within 12 months of discontinuation. The median WTP is 100 Meticais for all questions except the one about the partner finding out that she is using the method, for which the median answer is 70 Meticais. But there is little variation within woman in their self-reported WTP for the four methods' characteristics we asked about the two-by-two correlation coefficients between answers is between 0.7 and 0.85 .

${ }^{40} \mathrm{We}$ found that there was a high level of trust in health professionals, especially in government facilities: $80.6 \%(93.9 \%)$ of respondents said that they would certainly trust a message about pregnancy risks if it came from a nurse (doctor) in a government facility compared to $70 \%$ if this information came from a radio or TV program, $63.9 \%$ if it came from a pharmacist or $47 \%$ if it came from a school teacher, for instance.

${ }^{41}$ This, however, was not possible given funding limitations and the IRB requirement to destroy the respondents' contact details within 12 months.
} 
women before and after they received our information message. ${ }^{42}$

In the case of "intention to use contraception in the future", in addition to a ttest, we carry out a McNemar test, which is a popular test for before-after treatment comparisons of binary outcomes (Fagerland et al., 2013). ${ }^{43}$

After being given the "17 out of 20 women" information message, treated respondents are asked for the second time - 40 or so minutes after being first asked - to "Choose the number of beans which best reflects the probability that you would get pregnant in the coming 12 months if not using any contraceptive method". To avoid social desirability bias in answers to this question, we do not immediately ask this question but instead follow the information message by a question formulated closely to the wording of the message, namely: "Suppose there are 20 women exactly like you (...). Choose the number of beans which best reflects the number of women who, among these 20, would get pregnant in the coming 12 months if they did not use any contraceptive method." This offered respondents an opportunity to "please" the interviewer if they wished to do so. They should then have felt under no pressure to apply the newly acquired information to the more personal question of what they thought was their own probability of pregnancy absent contraception. If social desirability was an important driver of revisions to stated beliefs, then we would expect answers closer to the information provided (17) in the first question (about "20 women like you") than the second (about the respondent herself), but this is not the case. In fact, we can reject that the average answer to the first question is 17 (p-value of less than 0.0001), but not that the average answer to the second question is 17 (p-value: 0.12).

\footnotetext{
${ }^{42}$ The randomization however ensures that the average treatment effect on the treated should be equal to the average treatment effect on the non treated. A logit regression of selection into the subsample of women who received the information message on all the woman-invariant characteristics listed in Panel A of Table 1, four binary indicators for method used, baseline beliefs regarding the probability of pregnancy absent contraception, and a binary indicator for whether the woman says she intends to use contraception in the future before receiving the information message results in a p-value of 0.30 for the null hypothesis that the independent variables do not predict the outcome. See Table A-7 for a comparison of characteristics of women who received- and did not receive our information message.

${ }^{43}$ We follow Fagerland et al. (2013)'s recommendation and use the "mid-p" version of the test. The mid-p test avoids the loss of power associated with the exact test version while not violating the nominal level of the test in any of Fagerland et al. (2013)'s simulations, and it is well-suited to cases where the binary indicator has a small number of "zeroes" as we have here.
} 


\subsection{Results}

In Table 7, we report, for three samples of treated women, changes in average beliefs about the risk of pregnancy absent contraception, changes in intentions to use contraception in the future, and the p-values corresponding to two tests: a ttest of differences in the before- and after-information answers and, for the binary outcome, also a McNemar mid-p test.

We find that women update their stated expected chance of pregnancy in line with the new information (from 15.8 to 16.7 out of 20, on average, Table 7 Panel A) and these updates are statistically significant. As can be seen in Panel B, as expected a much larger upwards beliefs revision is observed among women who expected a risk of pregnancy absent contraception below 17 at baseline. The extent of the recalibration is striking, as it nearly fully realigns the women's beliefs with the information provided: women who expected a risk lower than 17 increase their belief by 0.90 (standard error: 0.08) bean for each bean below 17 at baseline. Conversely, women who at baseline expected a risk equal to 17 or larger reduce their belief of the risk of pregnancy by 0.98 (standard error: 0.23 ) bean for each bean above 17 at baseline. ${ }^{44}$

We also analyze the extent to which women internalize their beliefs updates, i.e., how changes in beliefs induced by our information message are reflected in their intentions to use contraception in the future compared to their baseline beliefs about the risk of pregnancy when not using contraception. This is useful for at least two reasons. First, it is informative in terms of the level of trust that women have about the information message. For instance, women may attribute more variance to beliefs updates than to their long-held beliefs, in which case the response to beliefs updates could be much lower than the response to baseline beliefs. Second, this exercise helps evaluate the plausibility of an interpretation of our experimental results as simply a reflection of social desirability. If respondents did not genuinely update their beliefs and reported an increased probability of pregnancy and increased intention to use simply to please the enumerator, then we would be unlikely to ob-

\footnotetext{
${ }^{44}$ Figures based on a regression of the before-after change in beliefs on the difference between the respondent's baseline belief and the reference risk of 17 out of 20 , separately for women with a baseline risk of 17 and above and those with a baseline risk below 17.
} 
serve a similar marginal effect of long-held beliefs and beliefs updates on intention to use.

In order to shed light on the extent of internalisation of beliefs updates, we estimate a logit model explaining future contraceptive intentions as a function of: all the women's characteristics listed in Panel A of Table 1, whether they are currently using contraception, their baseline beliefs about the risk of pregnancy when not using contraception, and their before-after treatment change in beliefs about the risk of pregnancy absent contraception - allowing for a different effect depending on whether women have a baseline expected risk below the reference figure of 17 $(85 \%)$ or equal to 17 and above.

We find that an increase of 5\%-points in the baseline expected probability of pregnancy absent contraception increases the intention to use contraception in the future by about 1\%-point (an average marginal effect of 0.0097 , standard error: 0.0038). For women with a baseline risk under the WHO reference rate of $85 \%$, an increase of 5\%-points in the beliefs update (before-after change) leads to an almost identical increase in intentions to use (an average marginal effect of 0.0095, standard error: 0.0048). For women with a baseline risk of $85 \%$ and above, beliefs updates have no effect on intentions to use contraception in the future - the marginal effect is -0.0005 (standard error: 0.0039).

While the extent to which women revise their beliefs in response to the information received is not exogenous, the estimated effects of belief revisions on intention to use contraception suggest that women fully internalize perceived increases in the risk of pregnancy, but do not respond to reductions in the perceived risk of pregnancy. The asymmetric responses to "good" and "bad" news are consistent with women preferring to err on the side of caution. Importantly, it seems difficult to rationalize the similarity between marginal responses to old- and newly increased beliefs by an explanation relying on social desirability as explained above.

Finally, we investigate the effect of our information message on intention to use contraception in the future and compare these experimental estimates to our model estimates.

One limitation of any policy counterfactual exercise is that the marginal response to a change in the value of a variable within the sample is used to predict the 
response to changes in the value of a variable coming from an external intervention. In particular, the counterfactual exercise uses the same estimated marginal effect to predict the effect of a change in beliefs irrespective of its direction. While not causal, our estimates above of the relationship between beliefs revisions and intention to use contraception suggest that only women with beliefs below the reference risk introduced in our experiment take their beliefs update into account.

Among women with baseline beliefs about the risk of pregnancy without contraception below 17 (Panel B), the average increase in the expected probability of pregnancy without protection is 4.7 beans out of 20 (and the p-value of a t-test comparing before- and after- treatment beliefs is $<0.001)$. A policy counterfactual increasing beliefs among women who expect a risk below 17 at baseline by the average change observed in the data and thus matching this increase in beliefs on average predicts an increase by $4.8 \%$-points in contraceptive use among this group (based on the model in Table 5 Column (7)). ${ }^{45}$ While budget restrictions prevented us from following women up to check the extent to which changes in their intended use of contraception translated into actual take-up, we find that intention to use among this group increases by $4.4 \%$-points in the experiment. Although less statistically significant than the effect observed in the (much larger) full sample (Panel A), this figure is close to our model prediction of $4.8 \%$-points, which is reassuring from the point of the reliability of our structural model estimates.

Women who are not currently using contraception are likely to be more responsive to new information about the risk of pregnancy absent contraception, although we cannot account for this heterogeneity when modeling contraceptive choices. ${ }^{46}$ Among women who are not using contraception, our treatment increases intention to use contraception by as much as $8.2 \%$-points (p-value of McNemar test: 0.03 ). Unsurprisingly, this is much larger than the predicted effect using the coefficients obtained when estimating the demand model on the whole sample - namely a

\footnotetext{
${ }^{45}$ For 36 women, this leads to beliefs of 20.7 out of 20 . If we cap beliefs at 20 , the policy counterfactual predicts an increase by $4.7 \%$-points. If instead we restrict the sample to treated women only and predict the change in contraceptive use based on their revised individual beliefs, the model predicts an increase in contraceptive use of 5.3\%-points among this group.

${ }^{46}$ In a model where using no contraception is an outcome, one cannot allow for heterogeneous responses to explanatory variables such as beliefs about pregnancy risk according to whether the respondent is using contraception.
} 
$1.6 \%$-point increase in actual use. ${ }^{47}$

\section{Conclusion}

Many women in low-income countries are not using contraception despite wanting to avoid pregnancy. This is especially puzzling given policy efforts to ensure that modern contraceptives are readily available at low- or no cost to the user.

In this paper we document, in a Mozambican setting, the subjective beliefs regarding contraception of women who wish to avoid pregnancy. We find that they hold plausible beliefs overall, except that they tend to underestimate the risk of pregnancy absent contraception and overestimate the risk of failure associated with hormonal methods.

Using these data to estimate a structural model of the choice between the main alternatives adopted by women in this country (including using no contraception), we find that supply issues and side-effects do not contribute much to low takeup, which calls for interventions beyond the current policy focus of improving the quantity and quality of contraceptive supply.

Our structural estimates also point at the importance of partners' preferences for contraceptive methods - as well as- and independently to partners' fertility preferences. Our findings therefore highlight the importance of involving men in interventions aimed at increasing contraceptive take-up. The extent to which men's preferences are amenable to change may however be limited in the short run.

Finally, we identify a new, promising avenue for immediate change, namely recalibrating beliefs about the risk of pregnancy absent contraception. We find support for this intervention via two independent exercises: first, in our structural model - identified from variation in beliefs and actual contraceptive use in our observational data - and second, through an experiment comparing women's beliefs and intentions to use contraception before- and after we inform them of the pregnancy risk absent contraception in the general population.

\footnotetext{
${ }^{47}$ This is the predicted effect on contraceptive use when increasing beliefs by the 1.5 beans average increase in the expected probability of pregnancy absent contraception observed in the sample of women who are currently not using contraception (see Table 7 Panel C).
} 
More precisely, our structural estimates indicate that increasing by 23.5\%-points the expected pregnancy risk absent contraception among the women who underestimate this risk would increase contraceptive take-up by about $4.8 \%$-points among this group (1.9\%-points overall). Among this group of women, our experiment increases the expected risk of pregnancy absent contraception by $23.5 \%$-points and intention to use contraceptives in the future by $4.4 \%$-points, which is close to our structural estimate of $4.8 \%$-points.

Among women not currently using contraception, intention to use contraceptives increases by as much as $8.2 \%$-points after informing them of the pregnancy risk absent contraception in the general population.

In Mozambique, modern contraceptive use (unmet need for contraception) went from $20.8 \%$ (18.9\%) in 2003 to $25.3 \%$ (23.1\%) in 2015. In Sub-Saharan Africa as a whole, contraceptive use (unmet need for contraception) went from 16\% (25.6\%) in 2000 to 26.3\% (24\%) in 2014 (all figures taken from World Development Indicators, 2019). Given this slow pace of progress - and even negative trend in the case of unmet need for contraception in Mozambique, the targeted information message we propose here appears to be a valuable low-cost instrument to increase contraceptive take-up in the short run. 


\section{References}

Adelekan, A., P. Omoregie, And E. Edoni (2014): "Male Involvement in Family Planning: Challenges and Way Forward," International Journal of Population Research, 2014.

Alsan, M. And M. WAnAmaker (2017): "Tuskegee and the Health of Black Men," The Quarterly Journal of Economics, 133, 407-455.

Álvarez, B. AND M. VERA-HernÁNDEZ (2013): "Exploiting Subjective Information to Understand Impoverished Children's Use of Health Care," Journal of Health Economics, 32, 1194-1204.

Ashraf, N., E. Field, AND J. LeE (2014): "Household Bargaining and Excess Fertility: An Experimental Study in Zambia," American Economic Review, 104, 2210-37.

Ashraf, N., E. Field, A. Voena, And R. Ziparo (2018): "Maternal Mortality Risk and the Gender Gap in Desired Fertility," Unpublished Manuscript.

Attanasio, O. P., C. Meghir, And A. Santiago (2011): "Education Choices in Mexico: Using a Structural Model and a Randomized Experiment to Evaluate Progresa," The Review of Economic Studies, 79, 37-66.

Bennear, L., A. Tarozzi, A. Pfaff, S. Balasubramanya, K. M. Ahmed, AND A. VAN GeEN (2013): "Impact of a Randomized Controlled Trial in Arsenic Risk Communication on Household Water-Source Choices in Bangladesh," Journal of Environmental Economics and Management, 65, 225-240.

Blumenthal, P., A. Voedisch, And K. Gemzell-Danielsson (2010): "Strategies to Prevent Unintended Pregnancy: Increasing Use of Long-Acting Reversible Contraception," Human Reproduction Update, 17, 121-137.

Boneva, T. And C. Rauh (2019): "Socio-Economic Gaps in University Enrollment: The Role of Perceived Pecuniary and Non-Pecuniary Returns," Unpublished manuscript. 
CARdell, N. S. (1997): "Variance Components Structures for the ExtremeValue and Logistic Distributions with Application to Models with Heterogeneity," Econometric Theory, 13, 185-213.

Cassidy, R., M. Groot Bruinderink, W. Janssens, and K. Morsink (2020): "The Power to Protect: Household Bargaining and Female Condom Use," Unpublished Manuscript.

Delavande, A. (2008): "Pill, Patch, or Shot? Subjective Expectations and Birth Control Choice," International Economic Review, 49, 999-1042.

Delavande, A., X. Giné, And D. McKenzie (2011): "Eliciting Probabilistic Expectations with Visual Aids in Developing Countries: How Sensitive Are Answers to Variations in Elicitation Design?" Journal of Applied Econometrics, 3, 479-497.

DelaVAnde, A. AND H.-P. KoHLer (2012): “The Impact of HIV Testing on Subjective Expectations and Risky Behavior in Malawi," Demography, 49, 10111036.

(2015): "HIV/AIDS-Related Expectations and Risky Sexual Behaviour in Malawi," The Review of Economic Studies, 83, 118-164.

Delavande, A. And B. Zafar (forthcoming): "University Choice: The Role of Expected Earnings, Non-pecuniary Outcomes and Financial Constraints," Journal of Political Economy.

Dowd, B. E., W. H. Greene, And E. C. Norton (2014): "Computation of Standard Errors," Health Services Research, 49, 731-750.

Doyle, K., R. G. Levtov, G. Barker, G. G. Bastian, J. B. Bingenheimer, S. Kazimbaya, A. Nzabonimpa, J. Pulerwitz, F. Sayinzoga, V. Sharma, ET AL. (2018): "Gender-Transformative Bandebereho Couples Intervention to Promote Male Engagement in Reproductive and Maternal Health and Violence Prevention in Rwanda: Findings from a Randomized Controlled Trial," PLoS One, 13. 
Duflo, E., R. Hanna, and S. P. Ryan (2012): "Incentives Work: Getting Teachers to Come to School," American Economic Review, 102, 1241-78.

Dupas, P. (2011): "Health Behavior in Developing Countries," Annual Review of Economics, 3, 425-449.

Dupas, P. AND E. Miguel (2017): "Impacts and Determinants of Health Levels in Low-Income Countries," in Handbook of Economic Field Experiments, Elsevier, vol. 2, 3-93.

Fagerland, M. W., S. Lydersen, And P. LaAke (2013): “The McNemar Test for Binary Matched-Pairs Data: Mid-P and Asymptotic Are Better than Exact Conditional," BMC Medical Research Methodology, 13, 91.

Glennerster, R., J. Murray, And V. Pouliquen (2019): "Mass Media and Modern Contraception Uptake: Experimental Evidence from Burkina Faso," Unpublished Manuscript.

Grollman, C., F. L. Cavallaro, D. Duclos, V. Bakare, M. Martínez Álvarez, and J. Borghi (2018): "Donor Funding for Family Planning: Levels and Trends Between 2003 and 2013," Health Policy and Planning, 33, 574-582.

Jones, M. P. (1996): "Indicator and Stratification Methods for Missing Explanatory Variables in Multiple Linear Regression," Journal of the American Statistical Association, 91, 222-230.

Krinsky, I. AND A. L. Rob B (1986): "On Approximating the Statistical Properties of Elasticities," The Review of Economics and Statistics, 715-719.

Krinsky, I., A. L. RobB, et AL. (1990): "On Approximating the Statistical Properties of Elasticities: A Correction," The Review of Economics and Statistics, 72, 189-190.

Lise, J., S. SeitZ, AND J. S Mith (2015): "Evaluating Search and Matching Models Using Experimental Data," IZA Journal of Labor Economics, 4, 16. 
Martinez-Bravo, M. And A. Stegmann (2019): "In Vaccines we Trust? The Effects of CIAs Vaccine Ruse on Immunization in Pakistan," CEMFI Working Paper No. 1713.

MISAU, INE AND ICF (2013): Moçambique Inquérito Demográfico e de Saúde 2011, Maputo/Moçambique: MISAU/Moçambique, INE, and ICF.

(2016): Inquérito de Indicadores de Imunização, Malária e HIV/SIDA em Moçambique (IMASIDA) 2015: Relatório de Indicadores Básicos, Maputo/Moçambique: MISAU/Moçambique, INE, and ICF.

Mumah, J. N., J. B. Casterline, K. Machiyama, M. Wamukoya, C. W. KABIRU, AND J. Cleland (2018): "Method-Specific Attributes that Influence Choice of Future Contraception Among Married Women in Nairobi's Informal Settlements," Studies in Family Planning, 49, 279-292.

Muralidharan, K. (2017): "Field Experiments in Education in Developing Countries," in Handbook of Economic Field Experiments, Elsevier, vol. 2, 323 385.

NAKAMURA, S. (2016): "Determinants of Contraceptive Choice Among Japanese Women: Ten Years After the Pill Approval," Review of Economics of the Household, 14, 553-575.

PritchetT, L. H. (1994): "Desired Fertility and the Impact of Population Policies," Population and Development Review, 20, 1-55.

Raj, A., M. Ghule, J. Ritter, M. Battala, V. Gajanan, S. Nair, A. Dasgupta, J. G. Silverman, D. Balaiah, and N. Saggurti (2016): “Cluster Randomized Controlled Trial Evaluation of a Gender Equity and Family Planning Intervention for Married Men and Couples in Rural India,” PloS one, 11.

SEDGH, G., L. S. Ashford, AND R. Huss Ain (2016): Unmet Need for Contraception in Developing Countries: Examining Women's Reasons for Not Using a Method, New York: Guttmacher Institute. 
Shattuck, D., B. Kerner, K. Gilles, M. Hartmann, T. NG'ombe, and G. Guest (2011): "Encouraging Contraceptive Uptake by Motivating Men to Communicate About Family Planning: The Malawi Male Motivator Project," American Journal of Public Health, 101, 1089-1095.

Singh, S., J. E. Darroch, And L. S. Ashford (2014): Adding It Up: The Costs and Benefits of Investing in Sexual and Reproductive Health 2014, New York New York Guttmacher Institute 2014.

TodD, P. E. AND K. I. WolPIN (2006): "Assessing the Impact of a School Subsidy Program in Mexico: Using a Social Experiment to Validate a Dynamic Behavioral Model of Child Schooling and Fertility," American Economic Review, 96, 1384-1417.

United Nations (2019): "Sustainable Development Goal 3: Ensuring Healthy Lives and Promote Well-Being for All at All Ages, Progress of Goal 3 in 2019," https://sustainabledevelopment.un.org/SDG3, [Online; accessed 9-September-2019].

VAn Der KlaAuw, W. (2012): "On the Use of Expectations Data in Estimating Structural Dynamic Choice Models," Journal of Labor Economics, 30, 521-554.

VAn Der KlaAuw, W. AND K. I. Wolpin (2008): "Social Security and the Retirement and Savings Behavior of Low-Income Households," Journal of Econometrics, 145, 21-42.

Vouking, M. Z., C. D. Evina, And C. N. TADEnfok (2014): "Male Involvement in Family Planning Decision Making in Sub-Saharan Africa: What the Evidence Suggests," The Pan African Medical Journal, 19.

WHO/RHR And CCP, Knowledge for Health Project (2018): Family Planning: A Global Handbook for Providers (2018 update), Baltimore and Geneva: CCP and WHO.

Williamson, L. M., A. Parkes, D. Wight, M. Petticrew, and G. J. Hart (2009): "Limits to Modern Contraceptive Use Among Young Women in Devel- 
oping Countries: A Systematic Review of Qualitative Research," Reproductive Health, 6, 3 .

Wiswall, M. AND B. ZAFAR (2015): "Determinants of College Major Choice: Identification Using an Information Experiment," The Review of Economic Studies, 82, 791-824.

World Development Indicators (2019): World Development Indicators, The World Bank.

Zakiyah, N., A. D. van Asselt, F. Roijmans, and M. J. Postma (2016): "Economic Evaluation of Family Planning Interventions in Low and Middle Income Countries; A Systematic Review," PloS one, 11, e0168447. 
Table 1: Summary Statistics for Method-Invariant Variables

\begin{tabular}{|c|c|c|c|}
\hline & Mean & SD & Count \\
\hline \multicolumn{4}{|l|}{ Panel A } \\
\hline Age $18-24$ & 0.32 & & 584 \\
\hline Age $25-34$ & 0.43 & & 584 \\
\hline Age $35-44$ & 0.22 & & 584 \\
\hline Age $45-49$ & 0.03 & & 584 \\
\hline \# Children & 2.61 & 1.72 & 584 \\
\hline No Schooling & 0.14 & & 584 \\
\hline Some Primary Schooling & 0.44 & & 584 \\
\hline Some Secondary Schooling & 0.42 & & 584 \\
\hline Urban & 0.47 & & 584 \\
\hline Maputo City & 0.22 & & 584 \\
\hline Maputo Province & 0.38 & & 584 \\
\hline Gaza Province & 0.39 & & 584 \\
\hline $\begin{array}{l}\text { Partner Wants More Children } \\
\text { or Wants them Earlier }\end{array}$ & 0.30 & & 584 \\
\hline Muslim & 0.03 & & 584 \\
\hline Christian & 0.47 & & 584 \\
\hline Catholic & 0.13 & & 584 \\
\hline Protestant & 0.03 & & 584 \\
\hline Other Religion & 0.30 & & 584 \\
\hline No Religion & 0.04 & & 584 \\
\hline Doesn't Know Religion & 0.01 & & 584 \\
\hline \multicolumn{4}{|l|}{ Panel B } \\
\hline No Method & 0.30 & & 584 \\
\hline Injections & 0.32 & & 556 \\
\hline Pill & 0.21 & & 557 \\
\hline Implants & 0.11 & & 502 \\
\hline Male Condom & 0.10 & & 562 \\
\hline "Unmet Need" $a$ & 0.23 & & 584 \\
\hline "Met Need" $a$ & 0.70 & & 584 \\
\hline Postpartum Amenorrheic After Wanted Child But Not FP Method ${ }^{a}$ & 0.06 & & 584 \\
\hline Need Unknown ${ }^{a}$ & 0.01 & & 584 \\
\hline Sex Last Month & 0.88 & & 584 \\
\hline Sex Last Quarter & 0.11 & & 584 \\
\hline Sex Activity Missing & 0.01 & & 584 \\
\hline \# Methods Known & 4.40 & 1.63 & 584 \\
\hline \# Methods Known (Main Four) & 2.73 & 0.60 & 584 \\
\hline$N$ & & & 584 \\
\hline
\end{tabular}

Source: Survey described in Section 2.2. Panel B reports the share of women who are using each method among the sample of those who know about this method. The number of observations reported in the last column is less than 584 for modern methods because not all women in our sample know every method. ${ }^{a}$ Unless specified otherwise, in this paper we refer to all women using no method as having an unmet need since all the women in our sample state that they do not want to get pregnant in the coming two years, are sexually active, and are not infecund. We also report descriptive statistics for a widely used DHS definition (e.g., in Sedgh et al., 2016), in which fecund, non-pregnant women who say they do not want to get pregnant in the coming two years can fall in one of four categories: (1) postpartum amenorrheic after wanted child, i.e. their menstruation has not returned since the birth of their last child within the last two years and this child was wanted at the time of the pregnancy, (2) unmet need, i.e. they are not using contraception and their period has returned since the birth of their last child or their period has not returned but their last child was not wanted, (3) met need, i.e. they are using contraception and (4) need unknown, i.e., the woman did not respond to all the questions required to establish her status. 
Table 2: Summary Statistics for Selected Method-Specific Variables

\begin{tabular}{|c|c|c|c|c|c|c|}
\hline & If using: & Condoms & Implants & Injections & No Method & Pill \\
\hline \multirow[t]{3}{*}{ P(Pregnancy) } & Mean & 0.17 & 0.25 & 0.19 & 0.78 & 0.35 \\
\hline & $\mathrm{SD}$ & 0.27 & 0.25 & 0.23 & 0.26 & 0.3 \\
\hline & Obs. & 553 & 469 & 537 & 579 & 540 \\
\hline \multirow[t]{3}{*}{$\mathrm{P}(\mathrm{STD})$} & Mean & 0.14 & 0.79 & 0.78 & 0.75 & 0.78 \\
\hline & $\mathrm{SD}$ & 0.27 & 0.24 & 0.24 & 0.27 & 0.24 \\
\hline & Obs. & 557 & 494 & 550 & 566 & 549 \\
\hline \multirow[t]{3}{*}{$\mathrm{E}$ (Method Cost) } & Mean & 22.47 & 25.64 & 27.03 & 0 & 14.07 \\
\hline & $\mathrm{SD}$ & 130.85 & 190.58 & 196.86 & 0 & 99.16 \\
\hline & Obs. & 554 & 498 & 549 & 584 & 545 \\
\hline \multirow[t]{3}{*}{$\mathrm{E}$ (Other Costs) } & Mean & 22.58 & 27.37 & 36.55 & 0 & 24.07 \\
\hline & SD & 171.70 & 194.50 & 249.78 & 0 & 208.58 \\
\hline & Obs. & 554 & 498 & 550 & 584 & 547 \\
\hline \multirow{3}{*}{$\begin{array}{l}\mathrm{P}(\text { Menstrual Irreg. } \\
\text { or Vaginal Infections) }\end{array}$} & Mean & 0.06 & 0.52 & 0.58 & 0 & 0.46 \\
\hline & $\mathrm{SD}$ & 0.18 & 0.26 & 0.30 & 0 & 0.31 \\
\hline & Obs. & 540 & 430 & 529 & 584 & 517 \\
\hline \multirow{3}{*}{$\begin{array}{l}\mathrm{P} \text { (Altered Libido, } \\
\text { Pleasure or Romance) }\end{array}$} & Mean & 0.26 & 0.15 & 0.19 & 0 & 0.14 \\
\hline & $\mathrm{SD}$ & 0.32 & 0.22 & 0.27 & 0 & 0.24 \\
\hline & Obs. & 533 & 418 & 513 & 584 & 497 \\
\hline \multirow{3}{*}{$\begin{array}{l}\text { P(Other Negative } \\
\text { Effects) }\end{array}$} & Mean & 0.06 & 0.33 & 0.31 & 0 & 0.31 \\
\hline & SD & 0.164 & 0.266 & 0.296 & 0 & 0.272 \\
\hline & Obs. & 539 & 440 & 523 & 584 & 516 \\
\hline P(Pregnancy after & Mean & 0.81 & 0.69 & 0.69 & 0.73 & 0.75 \\
\hline \multirow[t]{2}{*}{ Discontinuation) } & SD & 0.293 & 0.24 & 0.25 & 0.29 & 0.23 \\
\hline & Obs. & 552 & 462 & 534 & 575 & 539 \\
\hline \multirow[t]{3}{*}{ P(Partner Approval) } & Mean & 0.55 & 0.54 & 0.58 & 0.4 & 0.6 \\
\hline & $\mathrm{SD}$ & 0.32 & 0.30 & 0.32 & 0.34 & 0.31 \\
\hline & Obs. & 554 & 491 & 550 & 574 & 549 \\
\hline \multirow[t]{3}{*}{ P(Hide from Partner) } & Mean & 0.05 & 0.32 & 0.42 & 0.32 & 0.38 \\
\hline & $\mathrm{SD}$ & 0.18 & 0.30 & 0.34 & 0.33 & 0.32 \\
\hline & Obs. & 558 & 487 & 550 & 573 & 551 \\
\hline
\end{tabular}

Source: Survey described in Section 2.2. P(.) stands for "probability of event happening" and E(.) is the expectation operator. "Pregnancy" and "STD" refer to the perceived probability of pregnancy occurring or of contracting an STD, respectively, within 12 months. Costs are expected monthly costs. When the number of observations is less than 584, this is due to either some women not knowing of the relevant method (see the last column of Panel B of Table 1 for the number of women who know of each method), or to women not answering a question about a method. Waiting time corresponds to the middle of the interval chosen by respondents and is expressed in minutes. Top $1 \%$ in terms of costs and waiting times removed. 
Table 3: Perceived Probabilities of Approval by Partner

\begin{tabular}{lccccc}
\hline \hline & \multicolumn{5}{c}{ Current users of: } \\
& No Method & Injections & Pill & Implants & Male Condom \\
\hline Male Condom & 0.53 & 0.52 & 0.56 & 0.51 & 0.72 \\
Implants & 0.49 & 0.54 & 0.53 & 0.65 & 0.56 \\
Injections & 0.49 & 0.70 & 0.56 & 0.49 & 0.58 \\
No Method & 0.46 & 0.38 & 0.37 & 0.37 & 0.41 \\
Pill & 0.52 & 0.61 & 0.70 & 0.56 & 0.63 \\
\hline \hline
\end{tabular}

Source: Survey described in Section 2.2. Average perceived probabilities that the respondents' partners would approve of the partner choosing the alternative appearing in the row heading, by current method.

Table 4: Perceived Probabilities of Pregnancy within 12 Months

\begin{tabular}{lccccc}
\hline \hline & \multicolumn{5}{c}{ Current users of: } \\
& No Method & Injections & Pill & Implants & Male Condom \\
\hline Male Condom & 0.15 & 0.16 & 0.15 & 0.20 & 0.22 \\
Implants & 0.25 & 0.25 & 0.25 & 0.23 & 0.22 \\
Injections & 0.20 & 0.18 & 0.21 & 0.20 & 0.17 \\
No Method & 0.71 & 0.82 & 0.84 & 0.77 & 0.76 \\
Pill & 0.35 & 0.38 & 0.32 & 0.38 & 0.36 \\
\hline \hline
\end{tabular}

Source: Survey described in Section 2.2. Average perceived probabilities that the respondent would get pregnant within 12 months if she used the alternative appearing in the row heading, by current method. 
Table 5: Selected Nested Logit Estimates

\begin{tabular}{|c|c|c|c|c|c|c|c|}
\hline & (1) & (2) & (3) & (4) & (5) & (6) & (7) \\
\hline \multicolumn{8}{|c|}{ Effect of method-specific variables: } \\
\hline Spacing $\times \mathrm{P}($ pregnancy $)$ & $\begin{array}{l}-0.002 \\
(0.006)\end{array}$ & $\begin{array}{c}-0.002 \\
(0.006)\end{array}$ & $\begin{array}{l}-0.003 \\
(0.006)\end{array}$ & $\begin{array}{c}0.008 \\
(0.008)\end{array}$ & $\begin{array}{c}-0.013 \\
(0.013)\end{array}$ & $\begin{array}{c}0.009 \\
(0.011)\end{array}$ & $\begin{array}{c}0.001 \\
(0.006)\end{array}$ \\
\hline Limiting $\times \mathrm{P}($ pregnancy $)$ & $\begin{array}{l}-0.013 \\
(0.008)\end{array}$ & $\begin{array}{l}-0.012 \\
(0.008)\end{array}$ & $\begin{array}{l}-0.017^{*} \\
(0.009)\end{array}$ & $\begin{array}{l}-0.008 \\
(0.008)\end{array}$ & $\begin{array}{c}-0.033 * * \\
(0.016)\end{array}$ & $\begin{array}{l}-0.019 \\
(0.014)\end{array}$ & $\begin{array}{l}-0.009 \\
(0.007)\end{array}$ \\
\hline $\mathrm{P}(\mathrm{STD})$ & $\begin{array}{c}0.009 \\
(0.011)\end{array}$ & $\begin{array}{c}0.009 \\
(0.011)\end{array}$ & $\begin{array}{c}0.008 \\
(0.012)\end{array}$ & $\begin{array}{c}0.010 \\
(0.015)\end{array}$ & & & $\begin{array}{c}0.003 \\
(0.010)\end{array}$ \\
\hline $\mathrm{P}($ nausea $)$ & $\begin{array}{l}-0.009 * \\
(0.005)\end{array}$ & $\begin{array}{l}-0.009^{*} \\
(0.005)\end{array}$ & $\begin{array}{l}-0.008^{*} \\
(0.005)\end{array}$ & $\begin{array}{l}-0.010 \\
(0.006)\end{array}$ & & & $\begin{array}{l}-0.009^{*} \\
(0.004)\end{array}$ \\
\hline $\mathrm{P}($ menstrual irreg. $)$ & $\begin{array}{c}0.011 * * \\
(0.005)\end{array}$ & $\begin{array}{l}0.011 * * \\
(0.005)\end{array}$ & $\begin{array}{c}0.011 * * \\
(0.005)\end{array}$ & $\begin{array}{c}0.008 \\
(0.007)\end{array}$ & & & $\begin{array}{c}0.010^{* *} \\
(0.005)\end{array}$ \\
\hline $\mathrm{P}($ other neg. effect) & $\begin{array}{c}-0.015 * * \\
(0.007)\end{array}$ & $\begin{array}{c}-0.015 * * \\
(0.007)\end{array}$ & $\begin{array}{c}-0.015 * * \\
(0.007)\end{array}$ & $\begin{array}{c}-0.017^{*} \\
(0.009)\end{array}$ & & & $\begin{array}{c}-0.014 * * \\
(0.006)\end{array}$ \\
\hline $\mathrm{P}($ partner's approval) & $\begin{array}{c}0.060 * * * \\
(0.011)\end{array}$ & $\begin{array}{c}0.060 * * * \\
(0.011)\end{array}$ & $\begin{array}{c}0.062 * * * \\
(0.012)\end{array}$ & $\begin{array}{c}0.058 * * * \\
(0.018)\end{array}$ & & & $\begin{array}{c}0.061 * * * \\
(0.012)\end{array}$ \\
\hline $\begin{array}{l}\text { Partner wants the same } \\
\quad \times \mathrm{P} \text { (hide method) }\end{array}$ & $\begin{array}{c}-0.013 * * \\
(0.006)\end{array}$ & $\begin{array}{c}-0.013 * * \\
(0.006)\end{array}$ & $\begin{array}{c}-0.014 * * \\
(0.006)\end{array}$ & $\begin{array}{l}-0.009 \\
(0.007)\end{array}$ & & & $\begin{array}{c}-0.013 * * \\
(0.006)\end{array}$ \\
\hline $\begin{array}{l}\text { Partner wants more } \\
\text { kids } \times \mathrm{P}(\text { hide method })\end{array}$ & $\begin{array}{l}-0.003 \\
(0.011)\end{array}$ & $\begin{array}{l}-0.003 \\
(0.011)\end{array}$ & $\begin{array}{l}-0.005 \\
(0.011)\end{array}$ & $\begin{array}{l}-0.008 \\
(0.012)\end{array}$ & & & $\begin{array}{l}-0.002 \\
(0.011)\end{array}$ \\
\hline $\mathrm{P}($ obtain when needed $)$ & $\begin{array}{c}0.011 \\
(0.009)\end{array}$ & $\begin{array}{c}0.012 \\
(0.009)\end{array}$ & $\begin{array}{l}0.018^{*} \\
(0.009)\end{array}$ & $\begin{array}{c}0.015 \\
(0.010)\end{array}$ & & & $\begin{array}{c}0.011 \\
(0.009)\end{array}$ \\
\hline $\mathrm{E}($ direct costs) & $\begin{array}{c}0.001 \\
(0.001)\end{array}$ & $\begin{array}{c}0.001 \\
(0.001)\end{array}$ & $\begin{array}{c}0.003 * * * \\
(0.001)\end{array}$ & $\begin{array}{c}0.000 \\
(0.001)\end{array}$ & & & $\begin{array}{c}0.001 \\
(0.001)\end{array}$ \\
\hline $\mathrm{E}($ other costs $)$ & $\begin{array}{c}-0.001 * \\
(0.000)\end{array}$ & $\begin{array}{c}-0.001 * \\
(0.000)\end{array}$ & $\begin{array}{c}-0.004 * * * \\
(0.001)\end{array}$ & $\begin{array}{l}-0.000 \\
(0.000)\end{array}$ & & & $\begin{array}{c}-0.001^{*} \\
(0.000)\end{array}$ \\
\hline \multicolumn{8}{|c|}{ Effect of method-invariant variables on the probability of using no method rather than a hormonal method: } \\
\hline Partner wants more kids & $\begin{array}{l}0.468 * \\
(0.240)\end{array}$ & $\begin{array}{l}0.441^{*} \\
(0.242)\end{array}$ & $\begin{array}{c}0.464^{*} \\
(0.254)\end{array}$ & $\begin{array}{l}0.518 * \\
(0.288)\end{array}$ & $\begin{array}{c}0.665^{* * *} * \\
(0.219)\end{array}$ & $\begin{array}{c}0.769 * * * \\
(0.274)\end{array}$ & $\begin{array}{c}0.531 * * \\
(0.246)\end{array}$ \\
\hline Limiting & $\begin{array}{l}-0.525^{*} \\
(0.301)\end{array}$ & $\begin{array}{l}-0.506^{*} \\
(0.300)\end{array}$ & $\begin{array}{l}-0.447 \\
(0.310)\end{array}$ & $\begin{array}{l}-0.212 \\
(0.362)\end{array}$ & $\begin{array}{l}-0.246 \\
(0.304)\end{array}$ & $\begin{array}{l}-0.120 \\
(0.365)\end{array}$ & $\begin{array}{c}-0.523^{*} \\
(0.302)\end{array}$ \\
\hline $\begin{array}{l}\mathrm{P}(\text { pregnancy) } \\
\text { absent contraception } \\
\mathrm{P}(\mathrm{STD}) \text { absent } \\
\text { contraception }\end{array}$ & & & & & & & $\begin{array}{c}-0.068 * * * \\
(0.022) \\
0.027 \\
(0.022)\end{array}$ \\
\hline \multicolumn{8}{|c|}{ Effect of method-invariant variables on the probability of using condoms rather than a hormonal method: } \\
\hline Partner wants more kids & $\begin{array}{c}0.186 \\
(0.359)\end{array}$ & $\begin{array}{c}0.211 \\
(0.360)\end{array}$ & $\begin{array}{c}0.064 \\
(0.380)\end{array}$ & $\begin{array}{c}0.157 \\
(0.388)\end{array}$ & $\begin{array}{c}0.292 \\
(0.343)\end{array}$ & $\begin{array}{c}0.278 \\
(0.362)\end{array}$ & $\begin{array}{c}0.216 \\
(0.353)\end{array}$ \\
\hline Limiting & $\begin{array}{c}0.634 \\
(0.429)\end{array}$ & $\begin{array}{c}0.641 \\
(0.426)\end{array}$ & $\begin{array}{c}0.659 \\
(0.452)\end{array}$ & $\begin{array}{l}0.916^{*} \\
(0.471)\end{array}$ & $\begin{array}{c}0.660 \\
(0.428)\end{array}$ & $\begin{array}{l}0.880^{*} \\
(0.458)\end{array}$ & $\begin{array}{c}0.572 \\
(0.421)\end{array}$ \\
\hline $\begin{array}{l}\mathrm{P}(\text { pregnancy }) \\
\text { absent contraception } \\
\mathrm{P}(\mathrm{STD}) \text { absent } \\
\text { contraception }\end{array}$ & & & & & & & $\begin{array}{l}-0.055^{*} \\
(0.033) \\
-0.039 \\
(0.034)\end{array}$ \\
\hline$N$ & 2761 & 2588 & 2638 & 1768 & 2650 & 1768 & 2761 \\
\hline
\end{tabular}

Source: Estimates of Equation (1) using own survey data described in Section 2.2. Robust standard errors in parentheses, $* \mathrm{p}<0.10 * * \mathrm{p}<0.05 * * * \mathrm{p}<0.01$. Full results reported in Table A-4. Missing values set to zero and indicators for missing values included in Columns (1), (2), (3) and (7). Column (2) includes only alternatives for whom women answered at least 13 out of 16 method-specific questions. Column (3) excludes women who answered a higher probability of pregnancy within 1 year than within 5 years. Columns (4) and (6) exclude alternatives with missing values. 


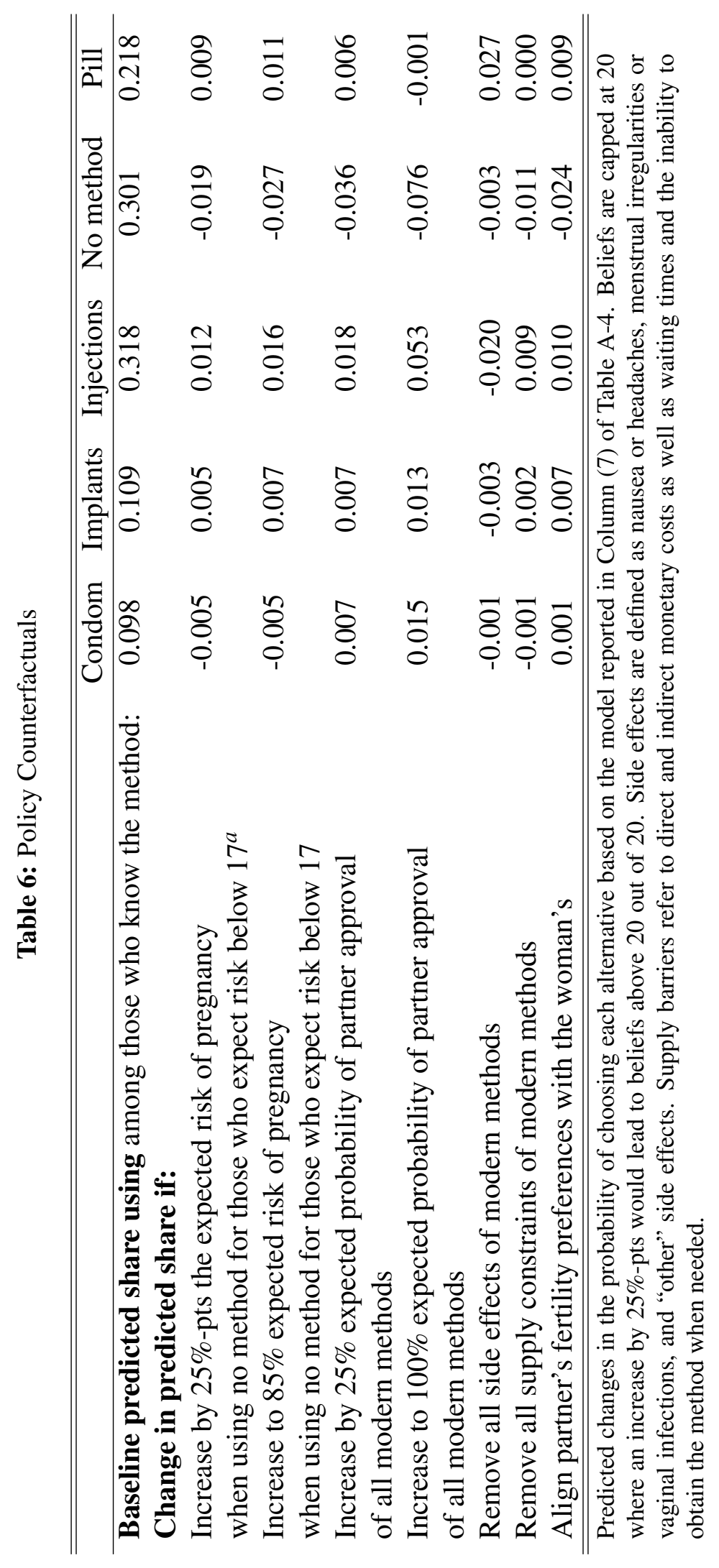




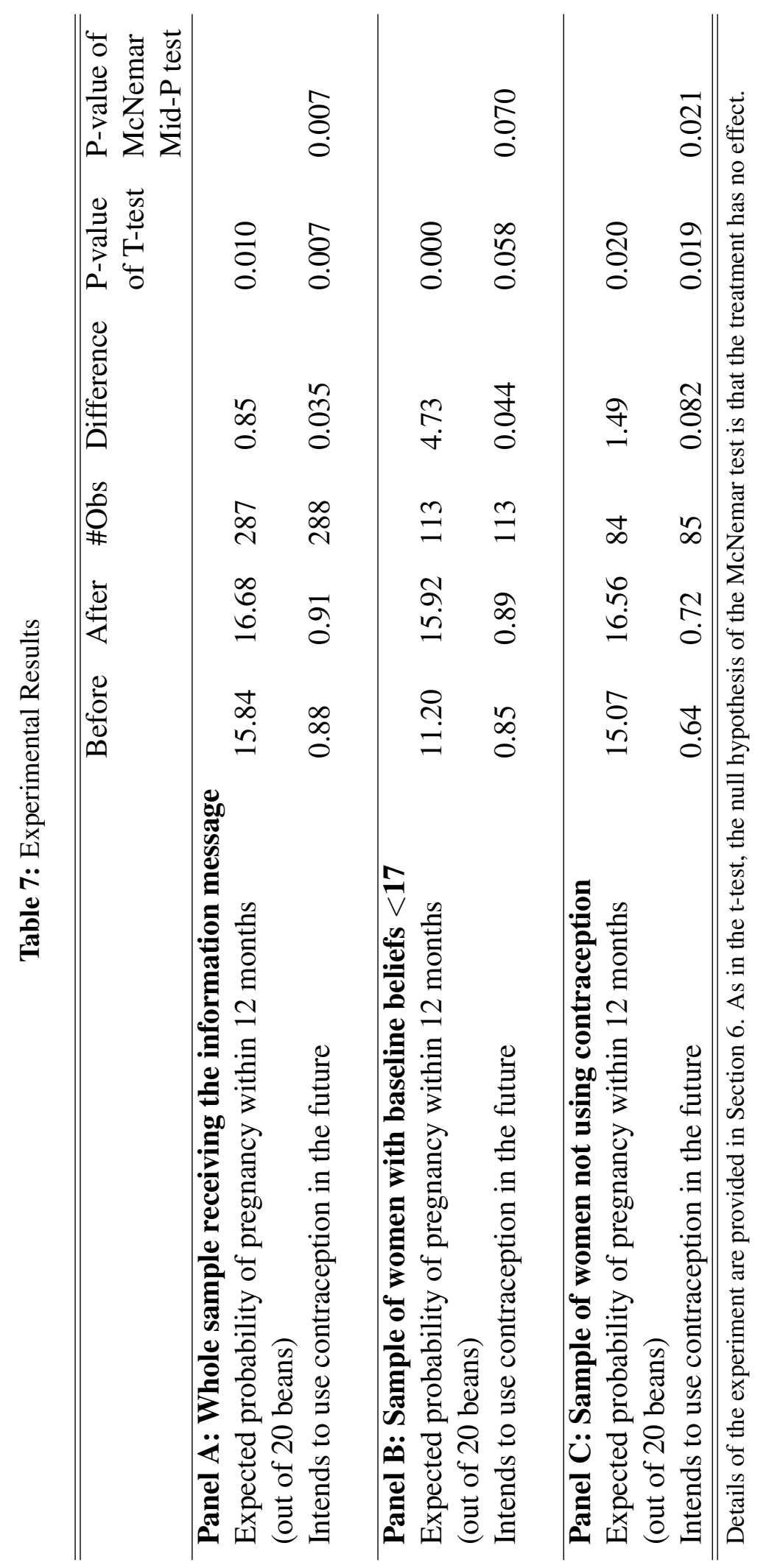




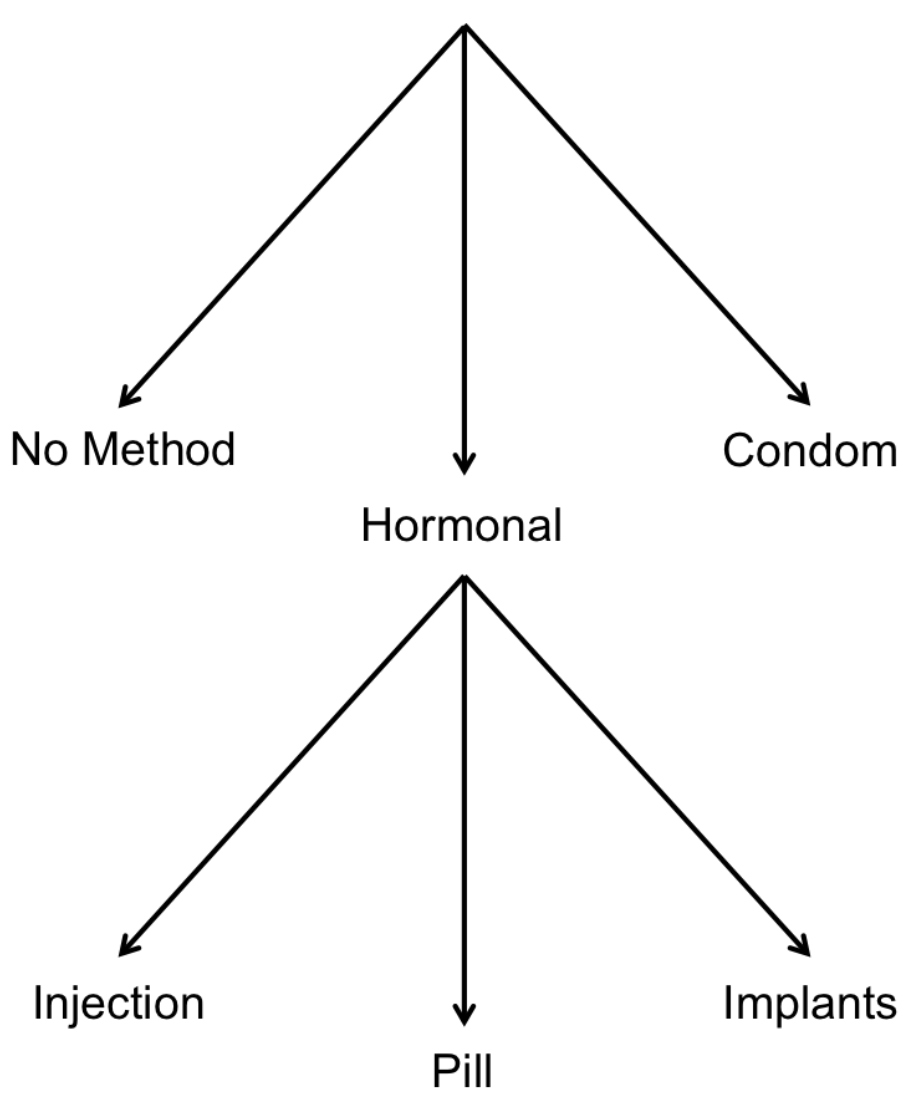

Figure 1: Nested Logit Tree 


\section{A-1 Appendix Tables}

Table A-1: Summary Statistics by Partner's Fertility Preferences

\begin{tabular}{|c|c|c|c|c|c|c|}
\hline \multirow{2}{*}{ Partner Fertility Preferences: } & \multicolumn{3}{|c|}{ Wants The Same } & \multicolumn{3}{|c|}{ Wants More } \\
\hline & Mean & SD & Count & Mean & SD & Count \\
\hline \multicolumn{7}{|l|}{ Panel A } \\
\hline Age $18-24$ & 0.32 & & 411 & 0.32 & & 173 \\
\hline Age 25-34 & 0.40 & & 411 & 0.49 & & 173 \\
\hline Age $35-44$ & 0.24 & & 411 & 0.17 & & 173 \\
\hline Age $45-49$ & 0.04 & & 411 & 0.02 & & 173 \\
\hline \# Children & 2.73 & 1.75 & 411 & 2.31 & 1.62 & 173 \\
\hline No Schooling & 0.13 & & 411 & 0.17 & & 173 \\
\hline Some Primary Schooling & 0.47 & & 411 & 0.37 & & 173 \\
\hline Some Secondary Schooling & 0.40 & & 411 & 0.46 & & 173 \\
\hline Urban & 0.44 & & 411 & 0.56 & & 173 \\
\hline Maputo City & 0.22 & & 411 & 0.24 & & 173 \\
\hline Maputo Province & 0.42 & & 411 & 0.30 & & 173 \\
\hline Gaza Province & 0.37 & & 411 & 0.46 & & 173 \\
\hline $\begin{array}{l}\text { Partner Wants More Children } \\
\text { or Wants them Earlier }\end{array}$ & 0.00 & & 411 & 1.00 & & 173 \\
\hline Muslim & 0.02 & & 411 & 0.04 & & 173 \\
\hline Christian & 0.47 & & 411 & 0.45 & & 173 \\
\hline Catholic & 0.13 & & 411 & 0.13 & & 173 \\
\hline Protestant & 0.04 & & 411 & 0.01 & & 173 \\
\hline Other Religion & 0.30 & & 411 & 0.30 & & 173 \\
\hline No Religion & 0.03 & & 411 & 0.05 & & 173 \\
\hline Doesn't Know Religion & 0.01 & & 411 & 0.02 & & 173 \\
\hline \multicolumn{7}{|l|}{ Panel B } \\
\hline No Method & 0.27 & & 411 & 0.37 & & 173 \\
\hline Injections & 0.35 & & 396 & 0.26 & & 160 \\
\hline Pill & 0.23 & & 395 & 0.19 & & 162 \\
\hline Implants & 0.11 & & 354 & 0.12 & & 148 \\
\hline Male Condom & 0.09 & & 395 & 0.12 & & 167 \\
\hline Unmet Need $^{a}$ & 0.21 & & 411 & 0.28 & & 173 \\
\hline Met Need $^{a}$ & 0.73 & & 411 & 0.63 & & 173 \\
\hline Postpartum Amenorrheic After Wanted Child & 0.06 & & 411 & 0.08 & & 173 \\
\hline \multicolumn{7}{|l|}{ But Not Reported as FP Method ${ }^{a}$} \\
\hline Need Unknown ${ }^{a}$ & 0.00 & & 411 & 0.01 & & 173 \\
\hline Sex Last Month & 0.87 & & 411 & 0.89 & & 173 \\
\hline Sex Last Quarter & 0.12 & & 411 & 0.10 & & 173 \\
\hline Sex Activity Missing & 0.01 & & 411 & 0.01 & & 173 \\
\hline \# Methods Known & 4.40 & 1.59 & 411 & 4.39 & 1.74 & 173 \\
\hline \# Methods Known & 2.75 & 0.57 & 411 & 2.68 & 0.68 & 173 \\
\hline$N$ & & & 411 & & & 173 \\
\hline
\end{tabular}

Source: Survey described in Section 2.2. ${ }^{a}$ Following commonly used definitions, fecund, nonpregnant women who say they do not want to get pregnant in the coming two years can fall in one of four categories: (1) postpartum amenorrheic after wanted child, i.e. their menstruation has not returned since the birth of their last child within the last two years and this child was wanted at the time of the pregnancy, (2) unmet need, i.e. they are not using contraception and their period has returned since the birth of their last child or their period has not returned but their last child was not wanted, (3) met need, i.e. they are using contraception and (4) need unknown, i.e., the woman did not respond to all the questions required to establish her status. 
Table A-2: Comparison Between Sample and Population Characteristics

\begin{tabular}{lccc}
\hline \hline & Dataset & AIS 2015 (3 Provinces) & AIS 2015 (All) \\
\hline Panel A & & & \\
Age 18-24 & 0.32 & 0.23 & 0.28 \\
Age 25-34 & 0.43 & 0.36 & 0.33 \\
Age 35-44 & 0.22 & 0.30 & 0.29 \\
Age 45-49 & 0.03 & 0.11 & 0.10 \\
\# Children & 2.61 & 3.8 & 4.2 \\
No Schooling & 0.14 & 0.11 & 0.25 \\
Some Primary Schooling & 0.44 & 0.61 & 0.53 \\
Some Secondary Schooling & 0.42 & 0.29 & 0.22 \\
\hline Panel B & & & \\
No Method & 0.30 & 0.38 & 0.57 \\
Injections & 0.32 & 0.23 & 0.20 \\
Pill & 0.21 & 0.20 & 0.11 \\
Implants & 0.11 & 0.04 & 0.03 \\
Male Condom & 0.10 & 0.08 & 0.03 \\
\# Methods Known & 4.4 & 624 & $4.6^{*}$ \\
\hline$N$ & 584 & 2178 \\
\hline \hline
\end{tabular}

Sources: Survey described in Section 2.2 (Column 1); Maputo City, Maputo Province and Gaza Province samples of the 2015 AIDS Indicators Survey (MISAU, INE and ICF, 2016) (Column 2); All women interviewed for the 2015 AIDS Indicators Survey (MISAU, INE and ICF, 2016) (Column 3). *Refers to all women married or in union in the 2011 Demographic and Health Survey (MISAU, INE and ICF, 2013), since this question was not asked in the AIDS Indicators Survey. 
Table A-3: Summary Statistics for All Method-Specific Variables

\begin{tabular}{|c|c|c|c|c|c|c|}
\hline & If using: & Condoms & Implants & Injections & No Method & Pill \\
\hline \multirow[t]{3}{*}{ P(Pregnancy) } & Mean & 0.17 & 0.25 & 0.19 & 0.78 & 0.35 \\
\hline & SD & 0.268 & 0.252 & 0.231 & 0.258 & 0.3 \\
\hline & Obs. & 553 & 469 & 537 & 579 & 540 \\
\hline \multirow[t]{3}{*}{$\mathrm{P}(\mathrm{STD})$} & Mean & 0.14 & 0.79 & 0.78 & 0.75 & 0.78 \\
\hline & $\mathrm{SD}$ & 0.267 & 0.235 & 0.238 & 0.269 & 0.24 \\
\hline & Obs. & 557 & 494 & 550 & 566 & 549 \\
\hline \multirow[t]{3}{*}{$\mathrm{E}$ (Method Cost) } & Mean & 22.47 & 25.64 & 27.03 & 0 & 14.07 \\
\hline & $\mathrm{SD}$ & 130.848 & 190.582 & 196.857 & 0 & 99.159 \\
\hline & Obs. & 554 & 498 & 549 & 584 & 545 \\
\hline \multirow[t]{3}{*}{$\mathrm{E}$ (Other Costs) } & Mean & 22.58 & 27.37 & 36.55 & 0 & 24.07 \\
\hline & $\mathrm{SD}$ & 171.702 & 194.499 & 249.779 & 0 & 208.577 \\
\hline & Obs. & 554 & 498 & 550 & 584 & 547 \\
\hline \multirow[t]{3}{*}{$\mathrm{P}($ Obtaining on Time $)$} & Mean & 0.9 & 0.82 & 0.84 & 1 & 0.86 \\
\hline & SD & 0.169 & 0.223 & 0.224 & 0 & 0.201 \\
\hline & Obs. & 554 & 486 & 551 & 584 & 549 \\
\hline \multirow[t]{3}{*}{ E(Waiting Time) } & Mean & 18.75 & 23.34 & 23.46 & 0 & 21.56 \\
\hline & SD & 12.716 & 19.625 & 19.714 & 0 & 16.747 \\
\hline & Obs. & 536 & 464 & 525 & 584 & 535 \\
\hline \multirow[t]{3}{*}{ P(Nausea or Headache) } & Mean & 0.03 & 0.24 & 0.21 & 0 & 0.44 \\
\hline & $\mathrm{SD}$ & 0.116 & 0.265 & 0.258 & 0 & 0.319 \\
\hline & Obs. & 539 & 414 & 507 & 584 & 503 \\
\hline \multirow{3}{*}{$\begin{array}{l}\text { P(Menstrual Irreg. } \\
\text { or Vaginal Infections) }\end{array}$} & Mean & 0.06 & 0.52 & 0.58 & 0 & 0.46 \\
\hline & $\mathrm{SD}$ & 0.175 & 0.259 & 0.296 & 0 & 0.306 \\
\hline & Obs. & 540 & 430 & 529 & 584 & 517 \\
\hline P(Altered Libido, & Mean & 0.26 & 0.15 & 0.19 & 0 & 0.14 \\
\hline \multirow[t]{2}{*}{ Pleasure or Romance) } & SD & 0.323 & 0.219 & 0.271 & 0 & 0.235 \\
\hline & Obs. & 533 & 418 & 513 & 584 & 497 \\
\hline \multirow[t]{3}{*}{$\mathrm{P}($ Other Negative Effects) } & Mean & 0.06 & 0.33 & 0.31 & 0 & 0.31 \\
\hline & $\mathrm{SD}$ & 0.164 & 0.266 & 0.296 & 0 & 0.272 \\
\hline & Obs. & 539 & 440 & 523 & 584 & 516 \\
\hline $\mathrm{P}$ (Pregnancy after & Mean & 0.81 & 0.69 & 0.69 & 0.73 & 0.75 \\
\hline \multirow[t]{2}{*}{ Discontinuation) } & SD & 0.293 & 0.24 & 0.245 & 0.291 & 0.23 \\
\hline & Obs. & 552 & 462 & 534 & 575 & 539 \\
\hline \multirow[t]{3}{*}{ P(Parents Approval) } & Mean & 0.61 & 0.5 & 0.53 & 0.28 & 0.54 \\
\hline & SD & 0.31 & 0.304 & 0.311 & 0.278 & 0.313 \\
\hline & Obs. & 529 & 465 & 516 & 532 & 522 \\
\hline \multirow[t]{3}{*}{ P(Relig. Approval) } & Mean & 0.49 & 0.39 & 0.39 & 0.3 & 0.39 \\
\hline & SD & 0.35 & 0.309 & 0.307 & 0.299 & 0.317 \\
\hline & Obs. & 488 & 435 & 470 & 490 & 479 \\
\hline \multirow[t]{3}{*}{ P(Partner Approval) } & Mean & 0.55 & 0.54 & 0.58 & 0.4 & 0.6 \\
\hline & $\mathrm{SD}$ & 0.32 & 0.303 & 0.324 & 0.335 & 0.31 \\
\hline & Obs. & 554 & 491 & 550 & 574 & 549 \\
\hline
\end{tabular}




\begin{tabular}{llccccc}
\hline P(Friends Approval) & Mean & 0.56 & 0.49 & 0.51 & 0.27 & 0.54 \\
& SD & 0.321 & 0.312 & 0.315 & 0.27 & 0.317 \\
& Obs. & 535 & 471 & 529 & 544 & 526 \\
P(Hide from Partner) & Mean & 0.05 & 0.32 & 0.42 & 0.32 & 0.38 \\
& SD & 0.177 & 0.298 & 0.343 & 0.33 & 0.316 \\
& Obs. & 558 & 487 & 550 & 573 & 551 \\
\hline \hline
\end{tabular}

Source: Survey described in Section 2.2. P(.) stands for "probability of event happening" and E(.) is the expectation operator. "Pregnancy" and "STD" refer to the perceived probability of pregnancy occurring or of contracting an STD, respectively, within 12 months. Costs are expected monthly costs. When the number of observations is less than 584, this is due to either some women not knowing of the relevant method (see the last column of Panel B of Table 1 for the number of women who know of each method), or to women not answering a question about a method. Waiting time corresponds to the middle of the interval chosen by respondents and is expressed in minutes. Top $1 \%$ in terms of costs and waiting times removed. 


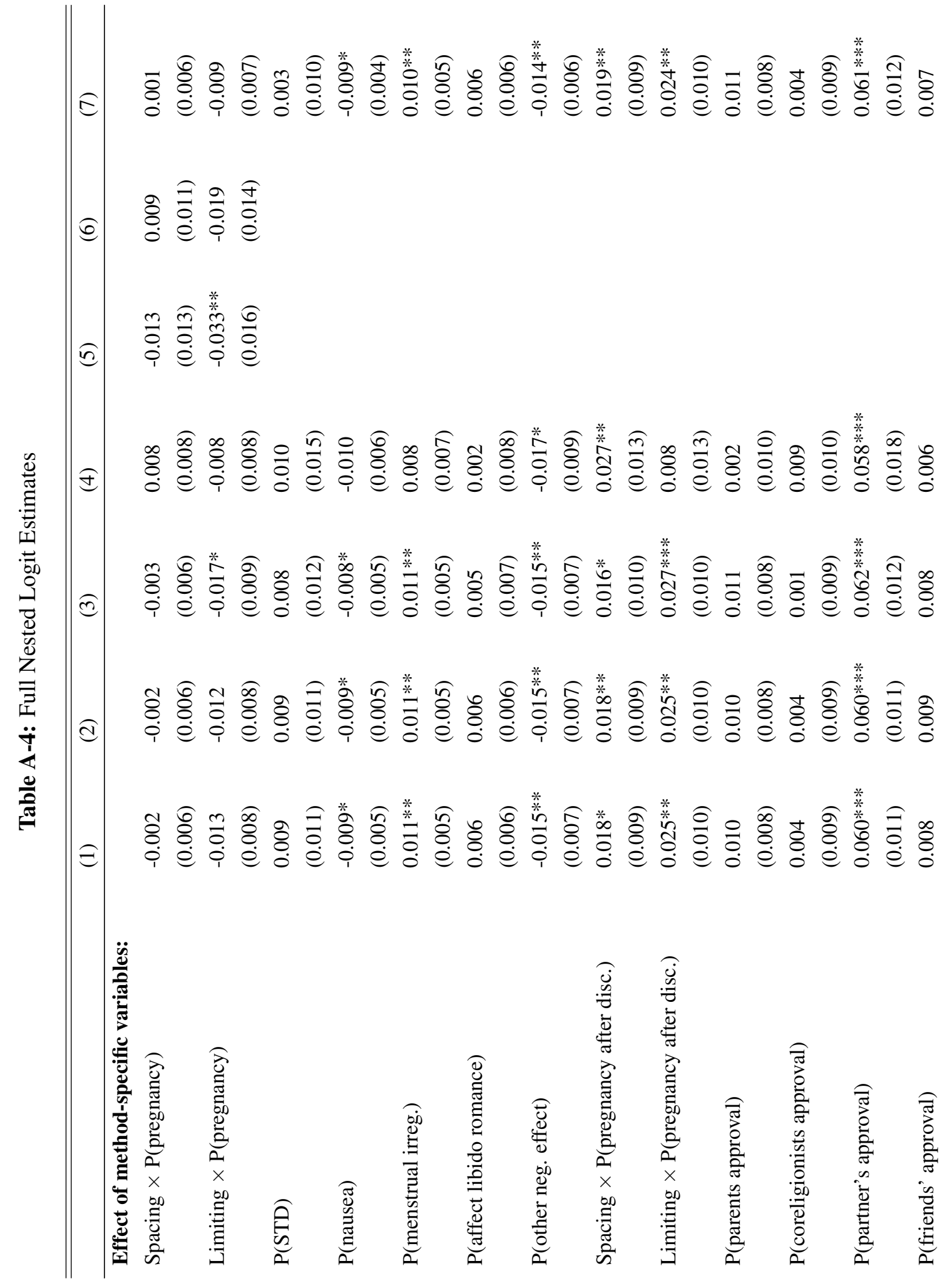




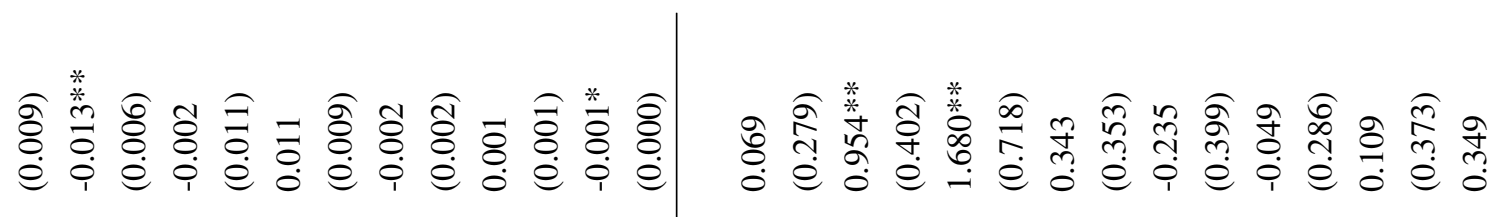

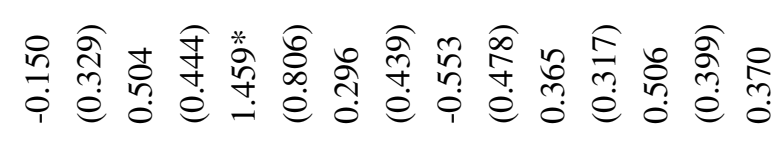

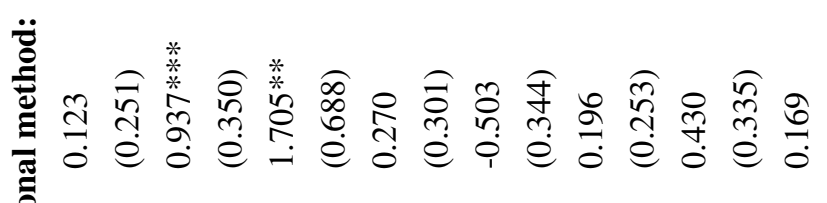

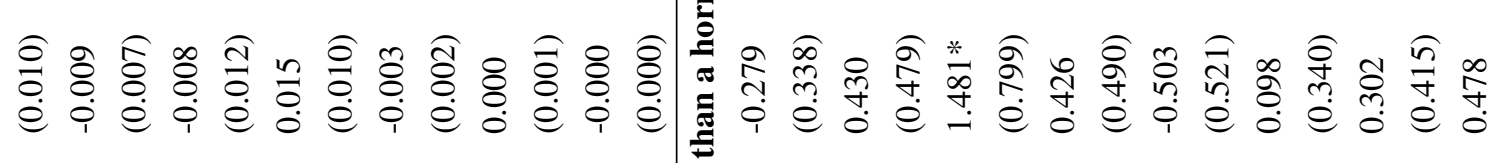

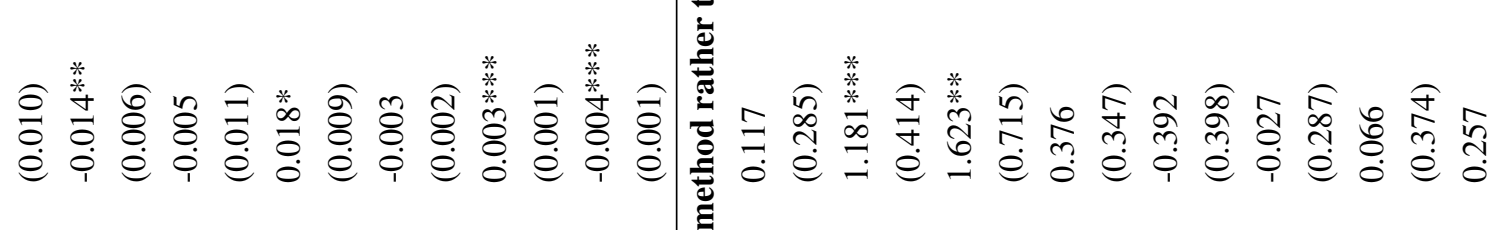

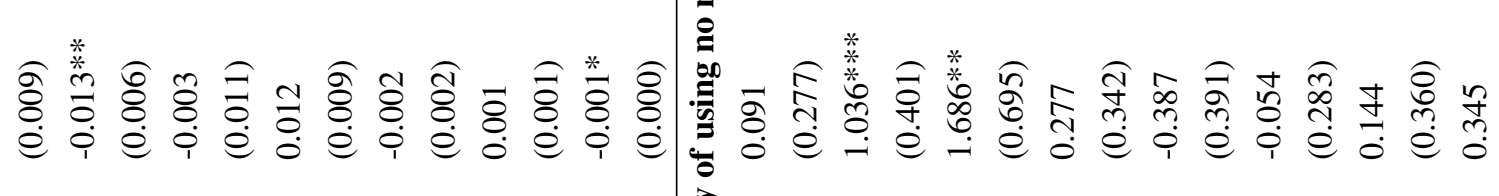

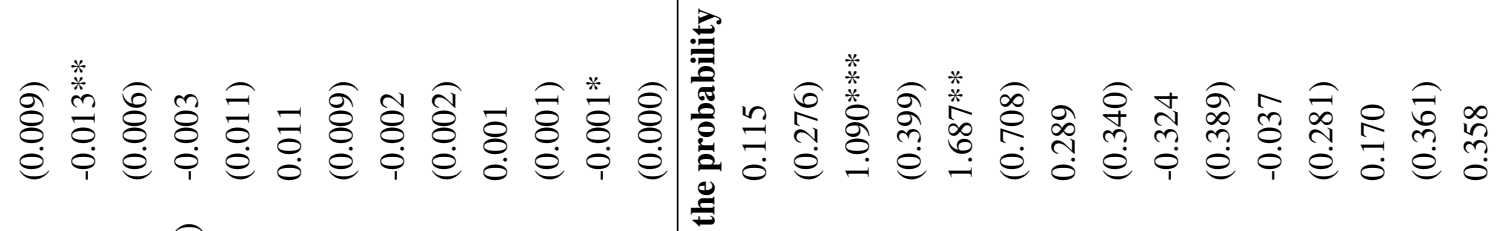

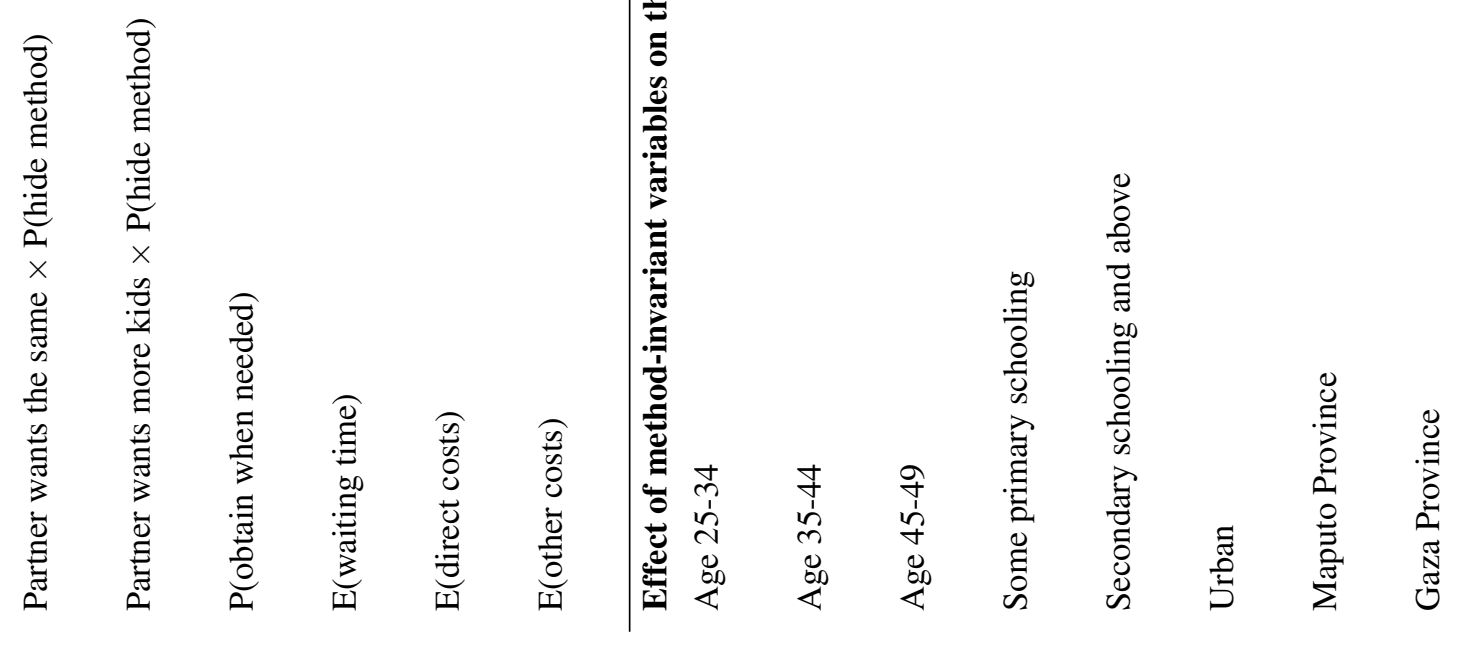




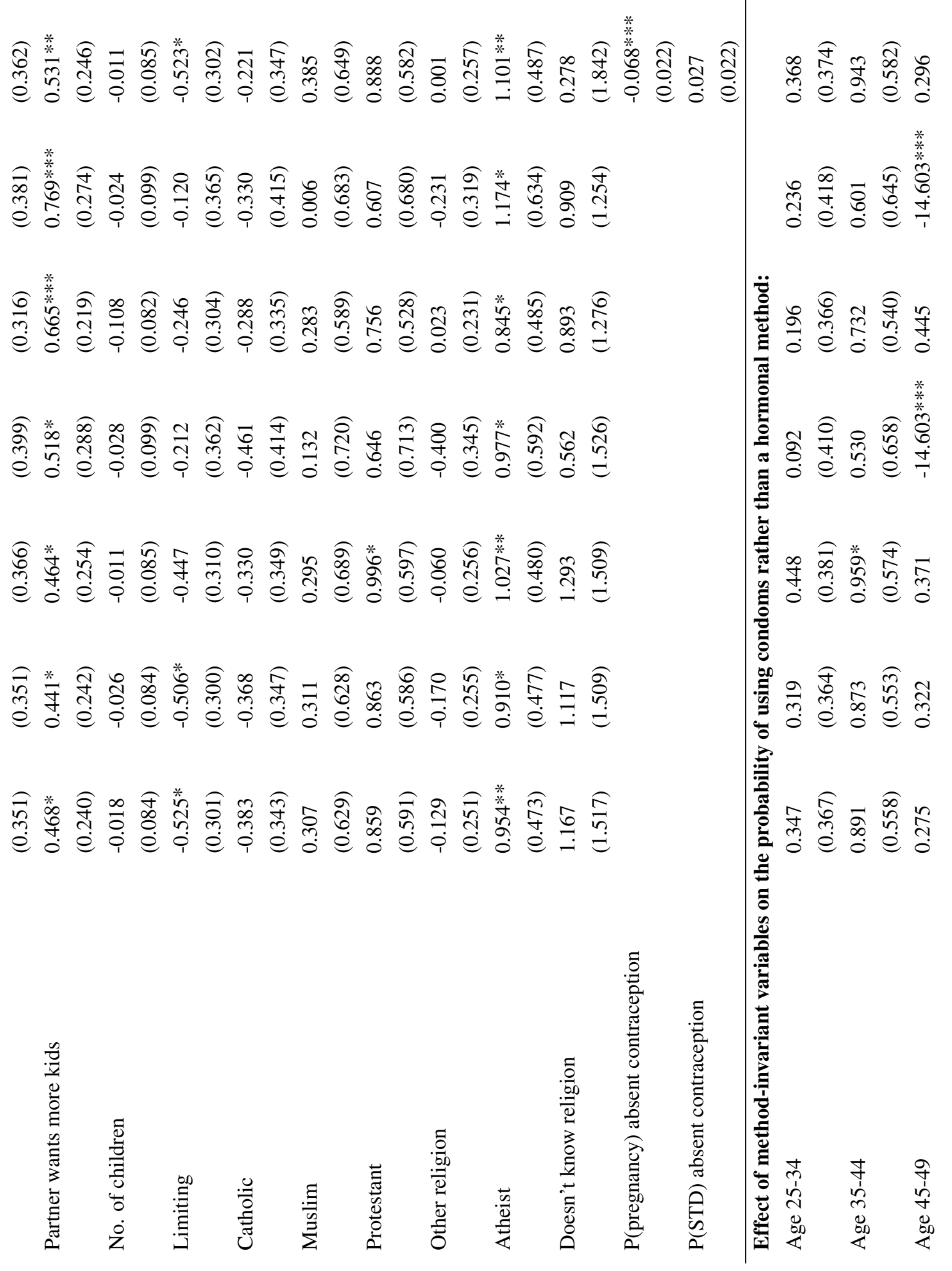




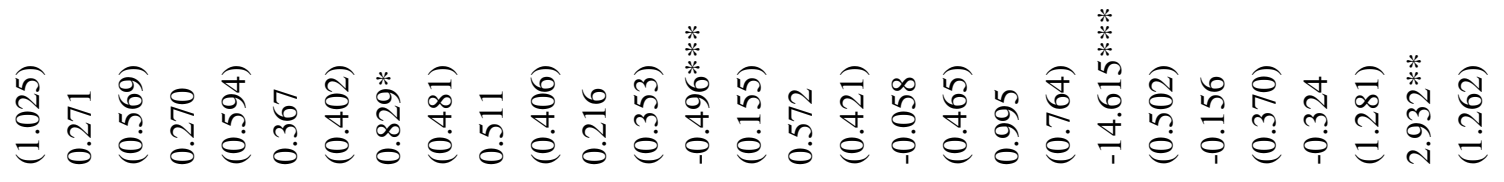

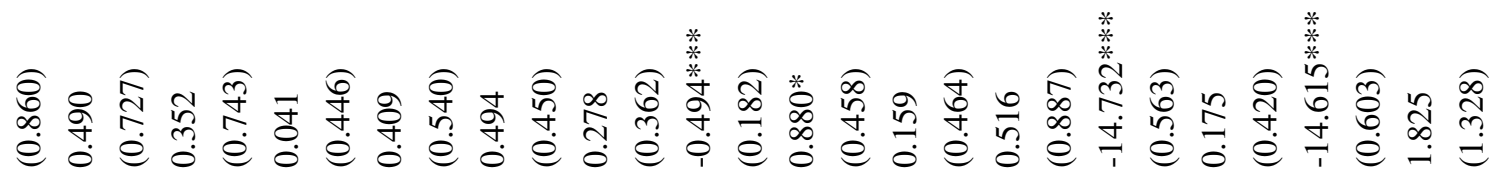

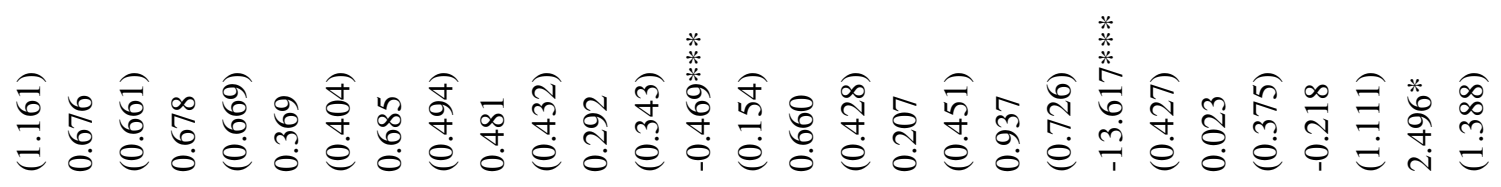

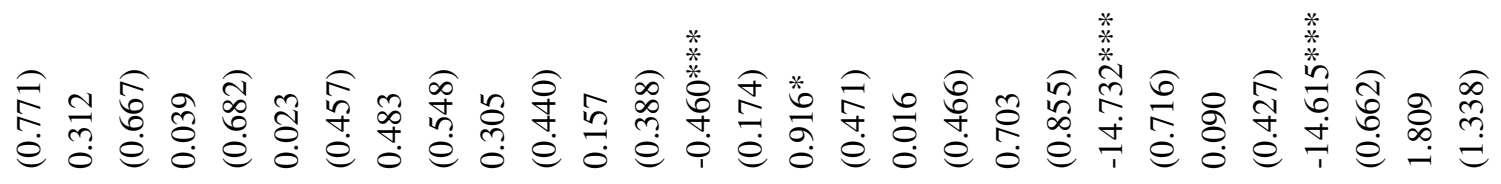

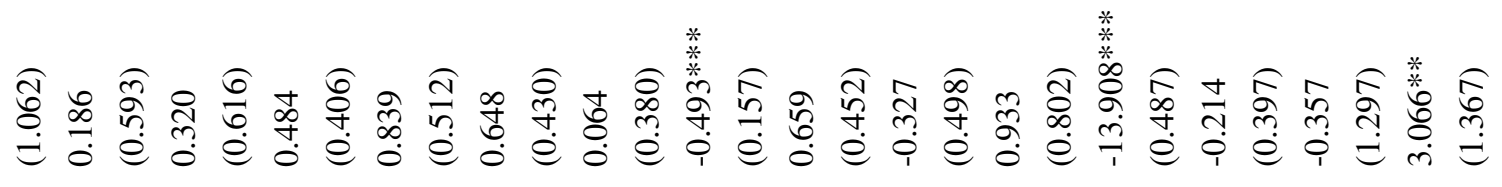

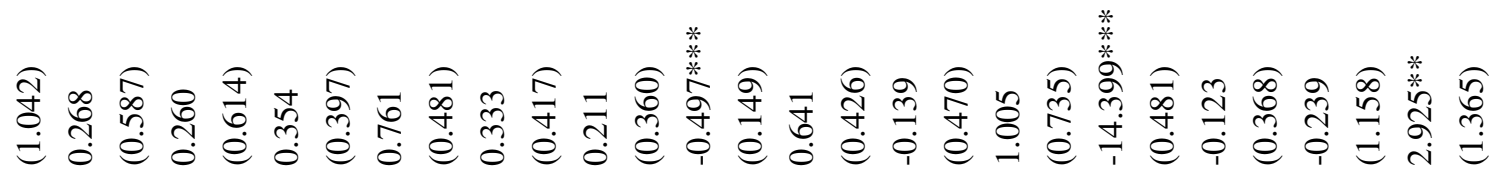

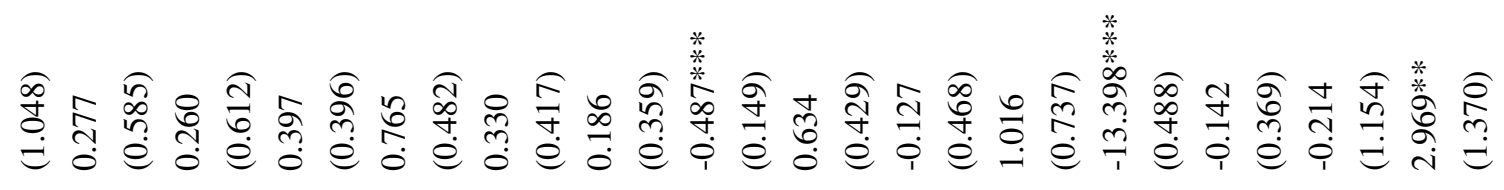

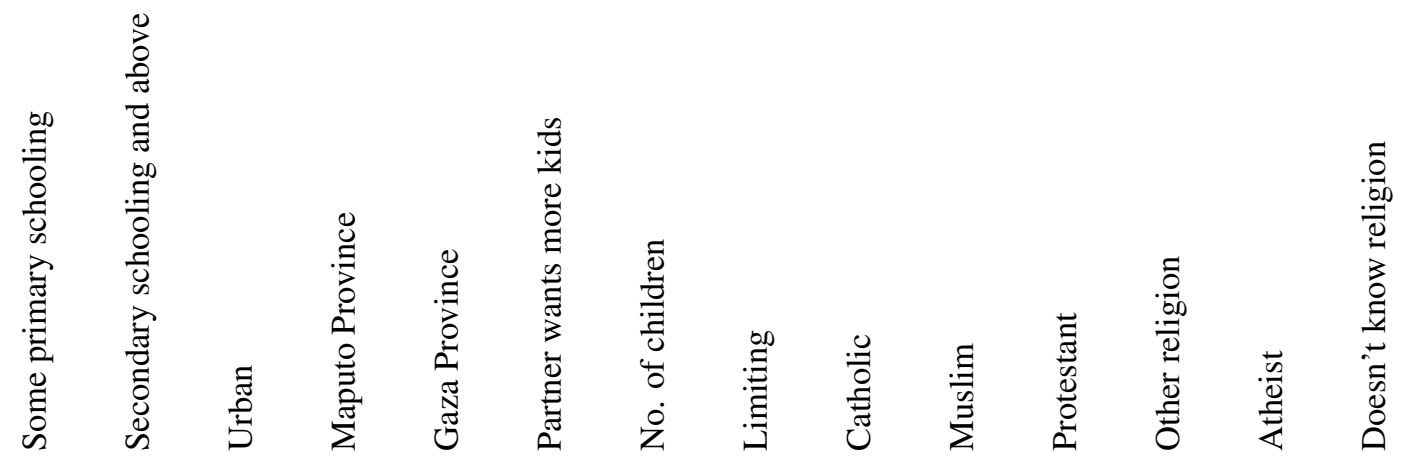




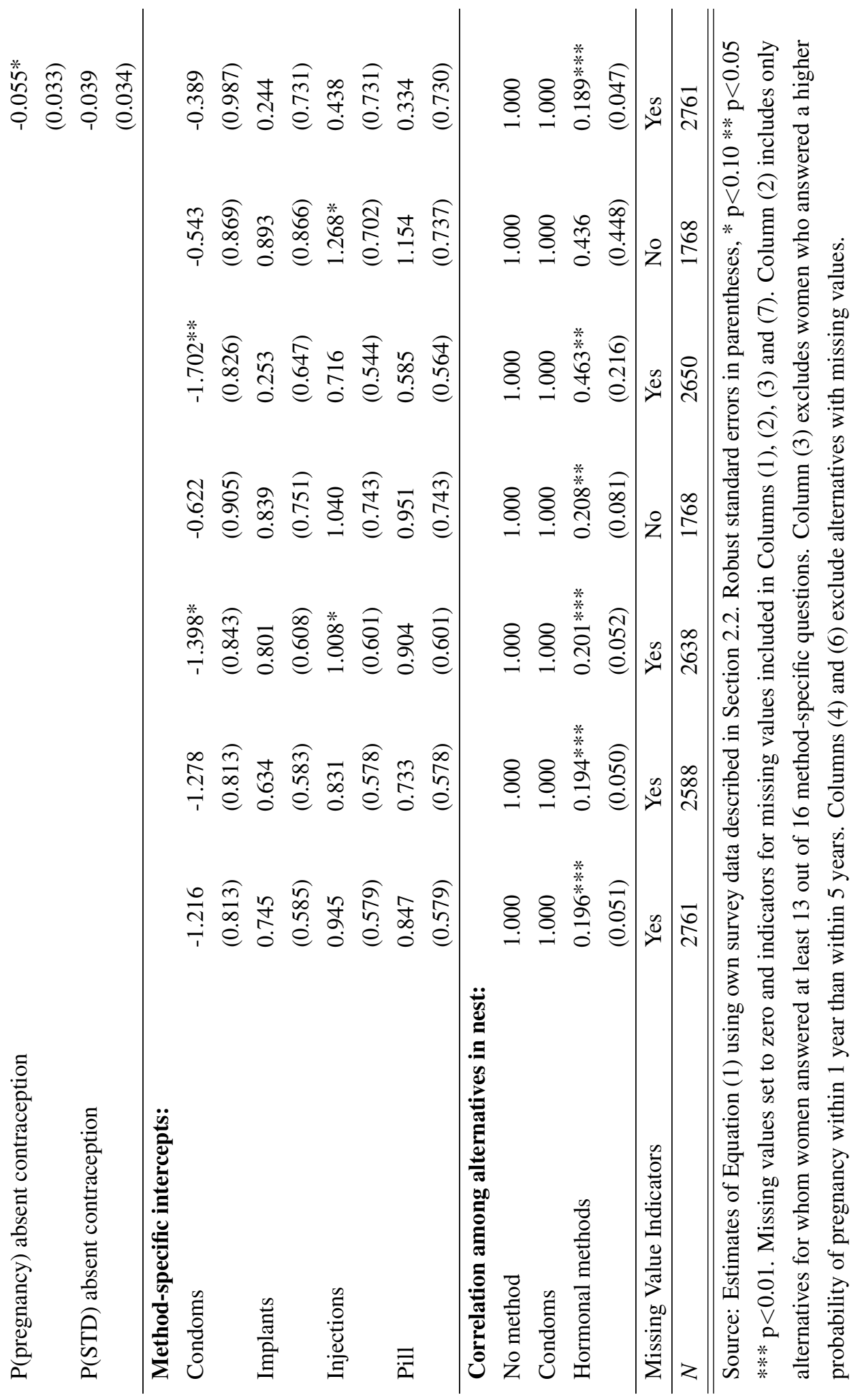


Table A-5: Selected Average Partial Effects Estimates

\begin{tabular}{lcc}
\hline \hline Average Partial Effect on the Probability of Choosing : & No Method & Injections \\
\hline Probability of Pregnancy Absent Contraception & -0.011 & 0.005 \\
& $(0.003)$ & $(0.001)$ \\
Probability of Other Negative Effect of Injections & 0.001 & -0.008 \\
& $\left(0.004 \times 10^{-1}\right)$ & $(0.003)$ \\
Probability of Partner Approving of Injections & -0.004 & 0.034 \\
& $(0.001)$ & $(0.008)$ \\
Indirect Cost of Injections & $0.005 \times 10^{-2}$ & $-0.004 \times 10^{-1}$ \\
& $\left(0.002 \times 10^{-2}\right)$ & $\left(0.002 \times 10^{-1}\right)$ \\
\hline Partner Wants More Kids & 0.088 & -0.036 \\
& $(0.039)$ & $(0.020)$ \\
Woman Wants to Limit- Rather than Space Fertility & -0.11 & 0.032 \\
& $(0.043)$ & $(0.027)$ \\
Sample size & 584 & 556 \\
\hline \hline
\end{tabular}

Authors' calculations based on the results reported in Column (7) of Table A-4, where probabilities can take values from 0 to 20 beans and the cost is expressed in Meticais. Standard errors obtained by the Krinsky-Robb method in parentheses (Krinsky and Robb, 1986; Krinsky et al., 1990; Dowd et al., 2014). Point estimates in the first four rows are obtained by taking the relevant derivative of the choice probabilities reported in footnote 36, evaluating it at the values of the regressors for each observation, and then averaging over the sample. For the binary indicators corresponding to the last two rows, point estimates are obtained by taking the difference in the choice probabilities when the binary indicator is equal to one and when it is equal to zero, for each observation, and then averaging over the sample. 
Table A-6: Beliefs and Duration of Use

\begin{tabular}{lccc}
\hline \hline & \multicolumn{2}{c}{$\begin{array}{c}\text { Effect of Year Started } \\
\text { Using Method }\end{array}$} \\
\hline & Coef. & S.E. & Observations \\
\hline P(pregnancy) & 0.104 & $(0.074)$ & 393 \\
P(STD) & 0.045 & $(0.087)$ & 394 \\
P(nausea) & -0.024 & $(0.083)$ & 391 \\
P(menstrual irreg.) & $0.163^{*}$ & $(0.093)$ & 393 \\
P(other neg. effect) & -0.035 & $(0.076)$ & 392 \\
P(affect libido romance) & 0.083 & $(0.079)$ & 390 \\
P(pregnancy after disc.) & 0.040 & $(0.064)$ & 386 \\
P(parents approval) & 0.035 & $(0.083)$ & 374 \\
P(coreligionists approval) & 0.083 & $(0.091)$ & 334 \\
P(partner's approval) & -0.062 & $(0.077)$ & 395 \\
P(friends' approval) & -0.022 & $(0.082)$ & 383 \\
P(hide method) & -0.001 & $(0.095)$ & 395 \\
P(obtain when needed) & -0.069 & $(0.053)$ & 396 \\
E(waiting time) & $0.416 *$ & $(0.245)$ & 379 \\
E(direct costs) & 1.337 & $(2.392)$ & 390 \\
E(other costs) & 0.535 & $(2.519)$ & 390 \\
\hline \hline
\end{tabular}

Each row corresponds to estimates obtained when regressing beliefs on the year the woman started using the contraceptive method she is currently using, a constant, and all the method-invariant characteristics included in $\mathrm{n}$ Panel A of Table 1. Standard errors in parentheses, $* \mathrm{p}<0.10 * * \mathrm{p}<0.05 * * *$. 
Table A-7: Characteristics of Treated and Untreated Samples

\begin{tabular}{|c|c|c|c|c|}
\hline & $\begin{array}{c}\text { Untreated } \\
\text { Mean }\end{array}$ & $\begin{array}{c}\text { Treated } \\
\text { Mean }\end{array}$ & Difference & $\begin{array}{c}\text { T-test } \\
\text { P-value }\end{array}$ \\
\hline Age 25-34 & 0.39 & 0.46 & -0.07 & 0.09 \\
\hline Age $35-44$ & 0.26 & 0.18 & 0.08 & 0.03 \\
\hline Age $45-49$ & 0.03 & 0.03 & 0.01 & 0.68 \\
\hline Some primary schooling & 0.47 & 0.42 & 0.05 & 0.23 \\
\hline Secondary schooling and above & 0.38 & 0.45 & -0.08 & 0.06 \\
\hline Urban & 0.47 & 0.48 & -0.02 & 0.69 \\
\hline Maputo Province & 0.40 & 0.37 & 0.03 & 0.50 \\
\hline Gaza Province & 0.40 & 0.39 & 0.01 & 0.81 \\
\hline Partner wants more kids & 0.29 & 0.30 & -0.00 & 0.90 \\
\hline No. of children & 2.76 & 2.45 & 0.32 & 0.03 \\
\hline Limiting & 0.39 & 0.36 & 0.02 & 0.55 \\
\hline Catholic & 0.16 & 0.09 & 0.07 & 0.02 \\
\hline Muslim & 0.02 & 0.04 & -0.02 & 0.12 \\
\hline Protestant & 0.03 & 0.03 & -0.00 & 0.95 \\
\hline Other religion & 0.30 & 0.30 & 0.01 & 0.89 \\
\hline Atheist & 0.02 & 0.05 & -0.03 & 0.04 \\
\hline Doesn't know religion & 0.01 & 0.01 & -0.00 & 0.97 \\
\hline Not Using & 0.31 & 0.30 & 0.01 & 0.75 \\
\hline Injections User & 0.30 & 0.31 & -0.00 & 0.97 \\
\hline Implant User & 0.10 & 0.09 & 0.00 & 0.86 \\
\hline Pill User & 0.20 & 0.20 & -0.00 & 0.95 \\
\hline Condoms User & 0.09 & 0.10 & -0.01 & 0.60 \\
\hline (Before-treatment) Intention to Use & 0.86 & 0.88 & -0.02 & 0.47 \\
\hline $\begin{array}{l}\text { Baseline Beliefs about Pregnancy Risk } \\
\text { Absent Contraception }\end{array}$ & 15.44 & 15.84 & -0.40 & 0.35 \\
\hline
\end{tabular}

Source: Survey described in Section 2.2. Treated women are women randomly selected to receive the pregnancy risk information message described in Section 6. Total sample size: 584, including 296 untreated and 288 treated women. 


\section{A-1 Appendix Figures}

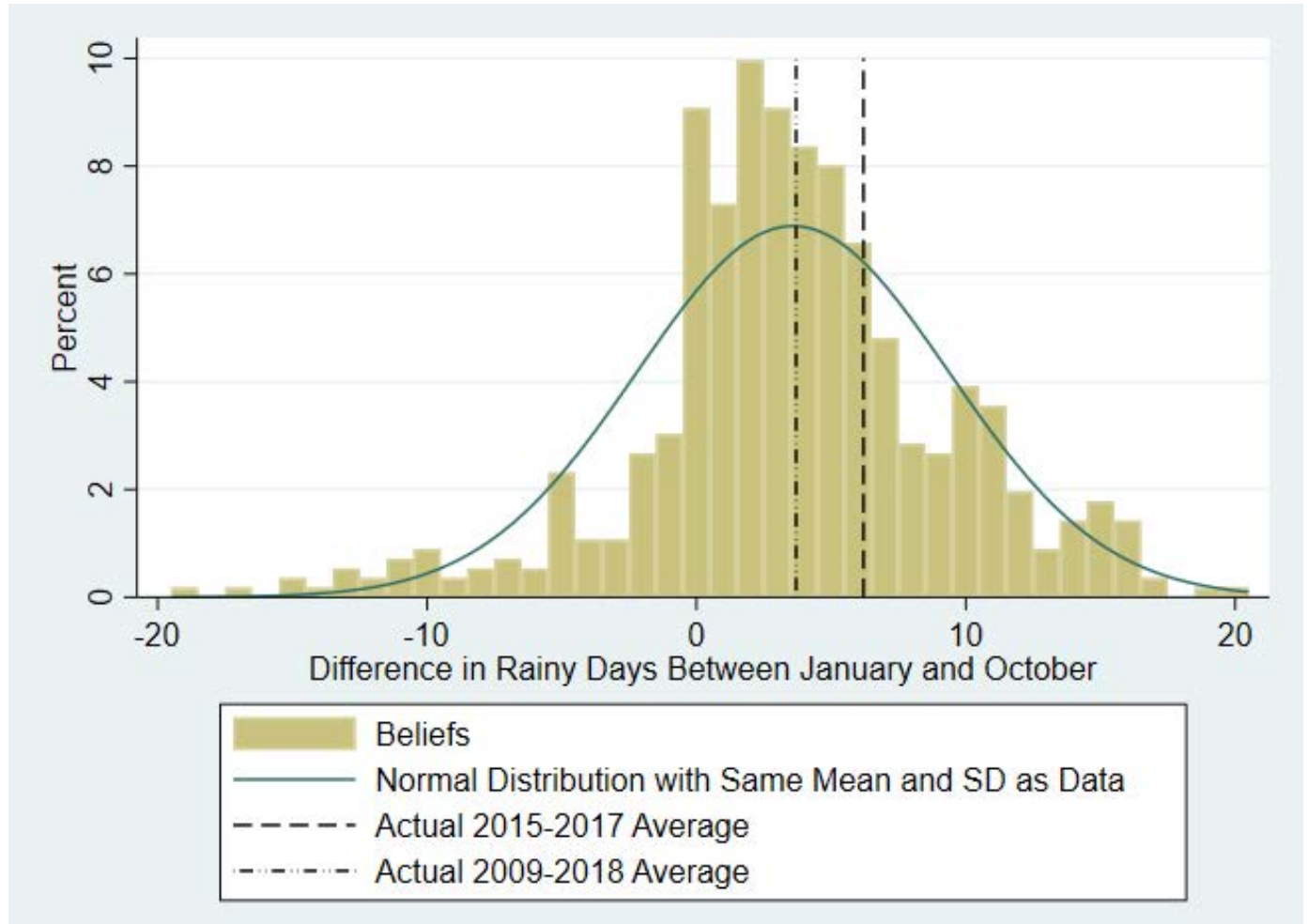

Figure A-1

Sources: https://weather-and-climate.com/average-monthly-Rainy-days, maputo, Mozambique ("Actual") and survey described in Section 2.2 ("Data"). 


\section{Subjective Probability of Pregnancy Within 12 Months}
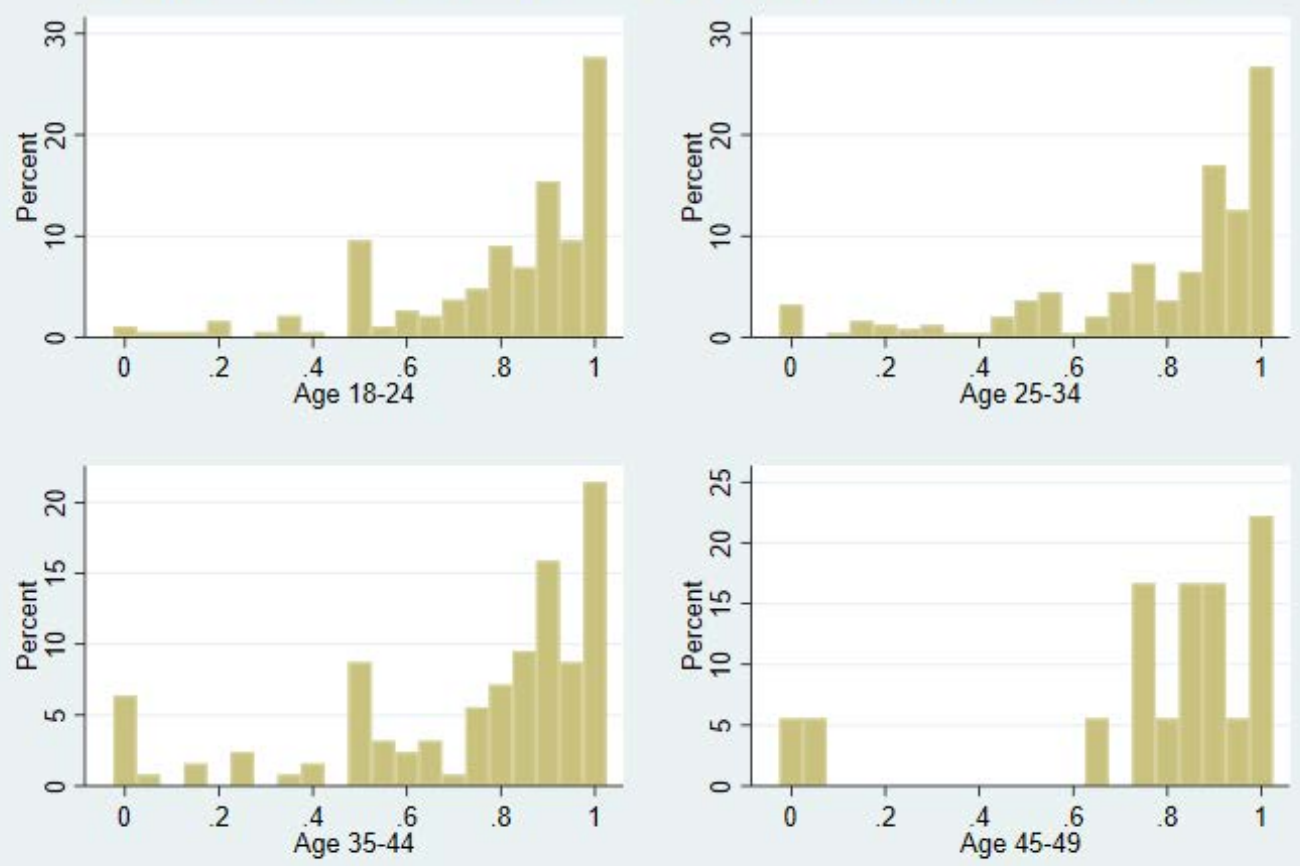

Figure A-2

Source: Survey described in Section 2.2. 